NBER WORKING PAPER SERIES

\title{
BUILDING NATIONS THROUGH SHARED EXPERIENCES: EVIDENCE FROM AFRICAN FOOTBALL
}

\author{
Emilio Depetris-Chauvin \\ Ruben Durante \\ Filipe R. Campante \\ Working Paper 24666 \\ http://www.nber.org/papers/w24666 \\ NATIONAL BUREAU OF ECONOMIC RESEARCH \\ 1050 Massachusetts Avenue \\ Cambridge, MA 02138 \\ May 2018
}

We thank Alberto Alesina, Sam Bazzi, Francesco Drago, Leopoldo Fergusson, Matthieu Couttenier, Quoc-Anh Do, Marcel Fafchamps, Ignacio Munyo, Wolfgang Stojetz, Jorge Tovar, Oliver Vanden Eynde, David Yanagizawa-Drott, Ekaterina Zhuravskaya, Jeff Staton, and especially Leonard Wantchekon for insightful comments. We also thank seminar participants at BU, Brown, FGV São Paulo, GWU, Harvard, Lausanne, Messina, Nottingham, NYU-Abu Dhabi, PSE, PUC Chile, PUC Rio, Sciences Po, SMU, Universidad Adolfo Hurtado, Universidad de Chile, Universidad Diego Portales, Universidad de Los Andes, Universidad del Rosario and Universitat Autonoma de Barcelona, and participants in the 2017 NBER Summer Institute in Development Economics, APSA Annual Meeting, the 20th Annual Conference of the SIOE, the 2016 Barcelona Summer Forum, the 2017 Oxford CSAE Conference, the 2016 MIPP Workshop in Political Economy and Political Science, the 2016 NEUDC, the 2016 LACEA Meeting, the 2016 RIDGE-LACEA Workshop in Political Economy, and the 2016 AL CAPONE meeting, and the 2018 Harvard Political Economy of Religion Seminar for helpful discussion. Christine Cai, Florin Cucu, Carlos Molina Guerra, Sebastian Melo, Francisco Eslava, and Catalina Morales, provided excellent research assistance. Emilio Depetris-Chauvin acknowledges financial support from CONICYT, FONDECYT Iniciación 11160290. The views expressed herein are those of the authors and do not necessarily reflect the views of the National Bureau of Economic Research.

NBER working papers are circulated for discussion and comment purposes. They have not been peer-reviewed or been subject to the review by the NBER Board of Directors that accompanies official NBER publications.

(C) 2018 by Emilio Depetris-Chauvin, Ruben Durante, and Filipe R. Campante. All rights reserved. Short sections of text, not to exceed two paragraphs, may be quoted without explicit permission provided that full credit, including $\odot$ notice, is given to the source. 
Building Nations Through Shared Experiences: Evidence from African Football

Emilio Depetris-Chauvin, Ruben Durante, and Filipe R. Campante

NBER Working Paper No. 24666

May 2018

JEL No. O12,Z20

\begin{abstract}
$\underline{\text { ABSTRACT }}$
We examine whether shared collective experiences can help build a national identity, by looking at the impact of national football teams' victories in sub- Saharan Africa. Combining individual survey data with information on official matches played between 2000 and 2015, we find that individuals interviewed in the days after a victory of their country's national team are less likely to identify with their ethnic group than with the country as a whole and more likely to trust people of other ethnicities than those interviewed just before. The effect is sizable and robust and is not explained by generic euphoria or optimism. Crucially, we find that national victories not only affect attitudes but also reduce violence: using plausibly exogenous variation from close qualifications to the African Cup of Nations, we find that countries that (barely) qualified experience significantly less conflict in the following six months than countries that (barely) did not. Our findings indicate that, even when divisions are deeply rooted, shared experiences can work as an effective nation-building tool, bridge cleavages, and have a tangible effect on violence.
\end{abstract}

Emilio Depetris-Chauvin

Department of Economics

Pontificia Universidad Católica de Chile

Santiago de Chile

edepetris@gmail.com

Ruben Durante

Sciences Po

Universitat Pompeu Fabra

IPEG, and CEPR

rubendurante@gmail.com
Filipe R. Campante

Harvard Kennedy School

79 JFK Street

Cambridge, MA 02138

and NBER

filipecampantehks@gmail.com 
"What has made sport so uniquely effective a medium for inculcating national feelings [...] is the ease with which even the least political or public individuals can identify with the nation as symbolized by young persons excelling [...]. The

imagined community of millions seems more real as a team of eleven named people. The individual, even the one who only cheers, becomes a symbol of his nation himself."

Eric Hobsbawm (1990, p.143)

\section{INTRODUCTION}

Many countries feature strong ethnic, linguistic, or regional cleavages, which can lead to tensions and even outright violence, with clearly detrimental consequences for economic development. ${ }^{1}$ Overcoming such cleavages has long been a crucial challenge in the consolidation of modern states, from 19th century Europe to present-day developing countries and even developed ones (e.g. Spain, Belgium).

This has led many countries to adopt so-called "nation-building" policies, aimed at forging a common identity, making citizens see themselves as part of the nation as a whole rather than of their specific group, and "feeling a sufficient amount of commonality of interests, goals and preferences [that] they do not wish to separate from each other" (Alesina and Reich, 2015; Alesina et al., 2017).

Examples of such policies typically include the provision of public services, from mass schooling to military conscription to infrastructure building (Tilly, 1975; Weber, 1976; Finer, 1975; Ramirez and Boli, 1987; Bandiera et al., 2018; Conversi, 2008; Bel, 2011). ${ }^{2}$ Implementing such policies, however, requires a substantial level of state capacity, and, as such, poses a clear conundrum: if internal fractionalization is an obstacle to the consolidation of a capable state, it can itself become a major hurdle for the adoption of policies that could overcome it.

In light of this challenge, countries also resort to other "softer" and less tangible nationbuilding tools which involve the use of symbols - such as the national flag or the national anthem - meant to evoke and reinforce national identity (Billig, 1995). Yet, while such "banal nationalism" may help maintain a national identity that has already been established, it is unlikely to be strong enough to make one emerge.

\footnotetext{
${ }^{1}$ For example, extensive evidence indicate that more ethnically diverse communities tend to experience more corruption and conflict, and less social cohesion, public good provision, and growth (Easterly and Levine, 1997; Alesina et al., 1999; Alesina and La Ferrara, 2005; Miguel and Gugerty, 2005).

2 Other countries attempted to integrate geographically segregated ethnic groups through large resettlement programs. See Bazzi et al. (2018) for a thorough empirical investigation of the effects of such a program for the case of Indonesia.
} 
Standing between these two extremes lie the experiences perceived by the citizens of a country as being collectively shared between them. Indeed, as pointed out by Anderson (1983) in his seminal work on nationalism, nations are fundamentally "imagined communities," and highly symbolic and emotionally charged experiences are crucial to make the image of the national communion live in each citizen's mind. Yet, to what extent such shared experiences can forge national identity, and how strong and long-lasting their effect might be, is an empirical question that remains under-explored.

We examine this issue by looking at one particular type of shared experiences: the success of national sports teams. Indeed, few realms of human endeavor are as effective as sports at creating imagined experiences, and it is not surprising that, from Hitler to Mandela, political leaders have frequently tried to harness the power of sports to strengthen national identities (Hilton, 2011; Carlin, 2008; Hobsbawm, 1990; Allison, 2000). We focus, in particular, on the impact of football - perhaps the one sport most associated with nationalistic fervor around the world - in Sub-Saharan Africa, a context marked by low levels of state capacity and where nation building, and the tension between particular versus national identities, are especially salient. ${ }^{3}$

We investigate how national football team victories in major international competitions affect the strength of ethnic identification, as opposed to national identity, as well as attitudes towards other ethnicities, and actual inter-ethnic violence. ${ }^{4}$ To this end, we combine different empirical approaches and use data from a variety of sources. First, to study the impact of national team victories on individual attitudes, we match data from four waves of the Afrobarometer survey with information on over 70 official matches by African teams held between 2000 and 2015. Our identification strategy exploits plausibly exogenous differences in the timing of the interviews relative to the timing of the matches. Specifically, we compare self-reported attitudes between individuals interviewed in the days immediately before a victory of their national team and individuals with the same ethnic background and in the

\footnotetext{
${ }^{3}$ See Miguel (2004) for a careful discussion of the mixed success of nation-building policies in postindependence Africa.

${ }^{4}$ Indeed, sports in general, and football in particular, has traditionally played a key role in nation-building in Africa. As argued by Darby (2002), football has greatly contributed to "construct a sense of national identity and to create a feeling of bonded patriotism cutting across tribal and ethnic allegiances." A prominent example of the unifying power of football in Africa is represented by the historical qualification of Ivory Coast to the 2006 FIFA World Cup under the charismatic leadership of Didier Drogba which, many argue, paved the way to a peaceful solution of the civil war that had ravaged the country for over five years (Stormer, 2006; Mehler, 2008). Looking beyond football, another notable example is the unexpected success of the South African national rugby team, the Springboks, in the 1995 Rugby World Cup, which president Nelson Mandela masterfully exploited in his effort to bridge racial divisions in the post-apartheid period. Outside of Africa, other cases of sports victories that spurred great patriotic fervor and primed national unity over racial and regional cleavages include the surprising victory of the U.S. ice hockey team against the USSR in the 1980 Winter Olympics (the so-called "Miracle on Ice"), and the success of France and Spain in the 1998 and the 2010 editions of the FIFA World Cup, respectively.
} 
same country, but interviewed in the days immediately after that same match, two groups that, we show, are comparable along most dimensions.

Applying this approach to over 28,000 respondents in 18 countries, we find that individuals interviewed after a national team victory are $4 \%$ less likely to report a strong sense of ethnic identity than those interviewed just before the match. This effect is sizable, corresponding to a $20 \%$ decrease in the average probability of ethnic self-identification, and quite persistent within the limited time window for which data are available (i.e., up to 30 days before and after the match), becoming even larger several days after the match.

Additional results further support the view that national team performance galvanizes supporters and tilts the balance between ethnic and national identity in favor of the latter. First, only a win affects ethnic sentiments and not the mere occurrence of an important match or any other outcome, including a defeat. Second, the effect is driven only by victories in high-stakes official games (i.e., Africa Cup of Nations and FIFA World Cup qualifiers and finals), as opposed to friendly matches. Third, the effect is substantially larger for victories against traditional rivals which are likely to trigger a stronger emotional reaction. Fourth, the effect is similar for wins in home and in away games, which indicates it is not driven by respondents' direct participation in the event.

We also find that the effect is weaker where the state is more present, specifically in ways that might lead to a stronger connection to the nation - roads, post office, schools. This suggests that shared experiences can work as a substitute for other forms of nation building. By the same token, the impact is stronger when there is greater ethnic diversity at the national level, as well as when the composition of the national team itself is more representative of that diversity. This is in line with a "role model" mechanism, where victories showcase how inter-ethnic cooperation can lead to achievement against a foreign opposing group.

These results are further corroborated by the fact that post-match respondents are also significantly more likely to trust other people, particularly members of other ethnicities. Crucially, respondents' lower emphasis on ethnic identity and higher trust in others do not merely reflect a generally positive mood due to post-victory euphoria. In fact, we find no effect of national team's victories on either trust in the ruling party or approval for the incumbent, a result which suggests that politicians' effort to use national teams' achievements to boost their own popularity may not pay off. Furthermore, we find that national team's victories do not affect respondents' optimism about their own or the country's economic prospects. ${ }^{5}$

We then explore whether, in addition to people's attitudes, national team victories have a tangible impact on violence and conflict. We combine the football data with data on the

\footnotetext{
${ }^{5}$ To better interpret our findings on respondents' attitudinal changes, we relate them to previous work in social psychology which has discussed various ways in which sports results may influence social identity.
} 
occurrence and severity of political violence events, available from the Armed Conflict Location \& Event Data Project (ACLED) for the period 1997-2013. Our approach exploits the quasi-randomness of qualification to the final tournament of the Africa Cup of Nations (ACN) for teams that, prior to the last game of the group stage, could still qualify. In other words, for each two teams in the same group that, going into the very last game, could still qualify, we attribute the one that actually qualified to the treatment group, and the one that barely failed to do so to the control group - two groups which, we show, are ex ante comparable along many dimensions.

We find that countries whose teams (barely) qualified to the ACN tournament experience significantly less conflict in the following six months than countries whose teams (barely) did not. This effect is sizable and significant, and robust to controlling for the intensity of conflict in the months prior to qualification. Interestingly, the effect is stronger for teams that had never qualified before or that had not qualified in a long time, and whose success was rather unexpected. ${ }^{6}$ Crucially, the reduction in conflict intensity that follows a successful qualification campaign appears to be quite persistent, up to several months after the event.

Taken together our findings indicate that shared collective experiences - such as important sports achievements - can be effective at priming sentiments of national unity and at attenuating even deeply-rooted ethnic mistrust, illustrating that soft tools can be effective in fostering a national identity. Moreover, we find that this has tangible effects on the prevalence of conflict. Even if the effect of these events is transient, our results suggest that it may last long enough to open a precious window of opportunity for political dialogue, negotiations and reforms capable of producing long-lasting improvements.

Our research contributes to various streams of literature, besides the aforementioned work on nation building. First, it relates to previous work on the determinants of ethnic identification which indicates that the strength of ethnic identification may be malleable by factors such as electoral competition, economic modernization, or whether an ethnic group holds power (Eifert et al., 2010; Robinson, 2014; Green, 2017). Yet, due to data limitations and identification issues, it has been difficult for these contributions to go beyond correlations and draw causal conclusions. Our paper fills this gap by providing robust causal evidence that the patriotic sentiments primed by important sports events can affect the strength of eth-

\footnotetext{
${ }^{6}$ Our finding that unexpected results are more consequential than expected ones is in line with previous evidence on the effect of sports events on various outcomes. For example, in their study on the impact of NFL games on intra-household violence Card and Dahl (2011) find that upset losses are associated with a $10 \%$ increase in violence toward female partners while expected ones have no impact. Similarly, Munyo and Rossi (2013) find that upset losses increase violent property crime whereas unexpected victories strongly reduce it, though both effects are extremely short-lived and mainly due to incapacitation.
} 
nic identity. ${ }^{7}$ We also add to the literature that has shown how shared collective experiences can affect individual attitudes in politically relevant ways (Madestam and Yanagizawa-Drott, 2012; Kaplan and Mukand, 2014).

Our paper also relates to previous work on the determinants of interpersonal trust which has documented how historical episodes, such as the slave trade, the introduction of the Napoleonic civil code, or the East German system of mass surveillance, had long-lasting effect on contemporary trust attitudes (Nunn and Wantchekon, 2011; Buggle, 2016; Jacob and Tyrell, 2010). Our findings indicate that other, more transitory factors, can also have a substantial impact on trust attitudes, particularly towards people of other ethnicities. In this respect, our results are especially related to recent work by Robinson (forthcoming) who shows that manipulating the salience of national identity in a 'lab-in-the-field" experiment improves inter-ethnic trust, and by Miguel (2004) who argues that nation-building policies can improve inter-ethnic cooperation.

Finally, our work contributes to the vast literature on the determinants of civil conflict, by documenting that priming national identity can contribute to reducing violence.

The paper is organized as follows: Section 2 introduces the data. Sections 3 and 4 present and discuss the empirical strategy and results for the individual- and country-level analysis, respectively. Section 5 concludes.

\section{DATA}

\subsection{National Football Teams’ Matches}

We collect information on all official matches played by men's national teams of various sub-Saharan African countries over the period 1990-2015; these data are available from the FIFA statistical office. ${ }^{8}$ In particular, we focus on matches played for both the qualifying and the tournament phases of the two most important competitions for African national football teams: the Africa Cup of Nations (ACN) and the FIFA World Cup (WC). ${ }^{9}$ For each match we have information on the date, the location, the opponent, the competition, the phase, and the final score. We use the information on the date of the match to combine the data with both the individual survey data and the conflict data described below. Overall, for the individual-level analysis, we use information from nearly 70 official matches played between 2002 and 2013 while the Afrobarometer surveys were administered. For the country-level

\footnotetext{
${ }^{7}$ For experimental evidence that sports affiliation can reduce ethnic identification, see Kurzban et al. (2001). Relatedly, looking at the specific case of cricket in India, Lowe (2018) finds that participation in team sports alongside people of other castes favors cross-cast friendships and integration.

${ }^{8}$ We disregard countries from the Maghreb region because, for these countries, Afrobarometer surveys did not include questions on ethnic identity.

${ }^{9}$ We also collect information on friendly matches, which we use for a robustness check reported below.
} 
conflict analysis, we also collect information on teams' standings in nine ACN qualifying rounds held between 1997 and 2013. In particular, we record all teams' standings before and after the final match of the group stage to identify teams that, prior to the last game, could still qualify to the tournament phase, and, among these, those that eventually did. ${ }^{10}$

\subsection{Survey Data on Individual AtTitudes}

We use individual survey data from four waves of the Afrobarometer conducted between 2002 and 2013. The Afrobarometer is a series of nationally representative surveys covering several African countries. Interviews are conducted in the local languages, and questions are standardized so that responses can be compared across countries. Questions are designed to assess respondents' attitudes on a range of issues, including attitudes towards democracy, political actors, markets, and civil society. For our analysis we focus on the questions regarding individuals' identification with the nation and with their own ethnic group, and trust in others, particularly in people from other ethnicities. In addition, we also use information on a range of respondents' personal characteristics, with particular regard to the main language spoken at home which, following Eifert et al. (2010), we use as a proxy for ethnic background. ${ }^{11}$ Overall, we use data from 47 survey rounds conducted in 24 sub-Saharan African countries.

Our main outcome variable is a measure of ethnic identification, which captures the strength of an individual's ethnic identity relative to national identity. The variable is based on responses to the following question: "Let us suppose that you had to choose between being a [National] and being a [respondent's ethnic group]. Which of these two groups do you feel most strongly attached to?”. While in round 2 of the Afrobarometer respondents could only choose between the options "national identity" and "group identity", in rounds 3 through 5 they could pick any of the following five options: 0 ("only [National]"), 1 ("more [National] than [Ethnic group]), 2 ("equally [National] and [Ethnic group])", 3 ("more[Ethnic group] than [National]"), and 4 (“only [Ethnic group]"). In order to compare respondents' answers across rounds, we construct a binary measure of ethnic identity that takes value 1 for all respondents in round 2 who chose the option "group identity", and for all respondents in rounds 3 through 5 who reported feeling "only ethnic" or "more ethnic that national".

10 The qualification phase for the 2013 ACN did not involve a group stage but sequential two-legged knockout pairs. We thus consider in our analysis only the last two-legged knock-out stage. Nonetheless, our quantitative and qualitative results do not depend on the inclusion of the 2013 qualification phase.

${ }^{11}$ Language is the best proxy for ethnic background available in all the waves of the Afrobarometer we use in our analysis. In fact, the Afrobarometer questionnaires did not include explicit questions about the respondent's ethnicity until recently. In Appendix Table A.2 we show that, for the waves for which data on ethnicity are available, our results are analogous if we include ethnic group fixed effects instead of language group fixed effects. 
Figure 1: Ethnic IDENTIFICATION Over Time AND ACRoss Countries

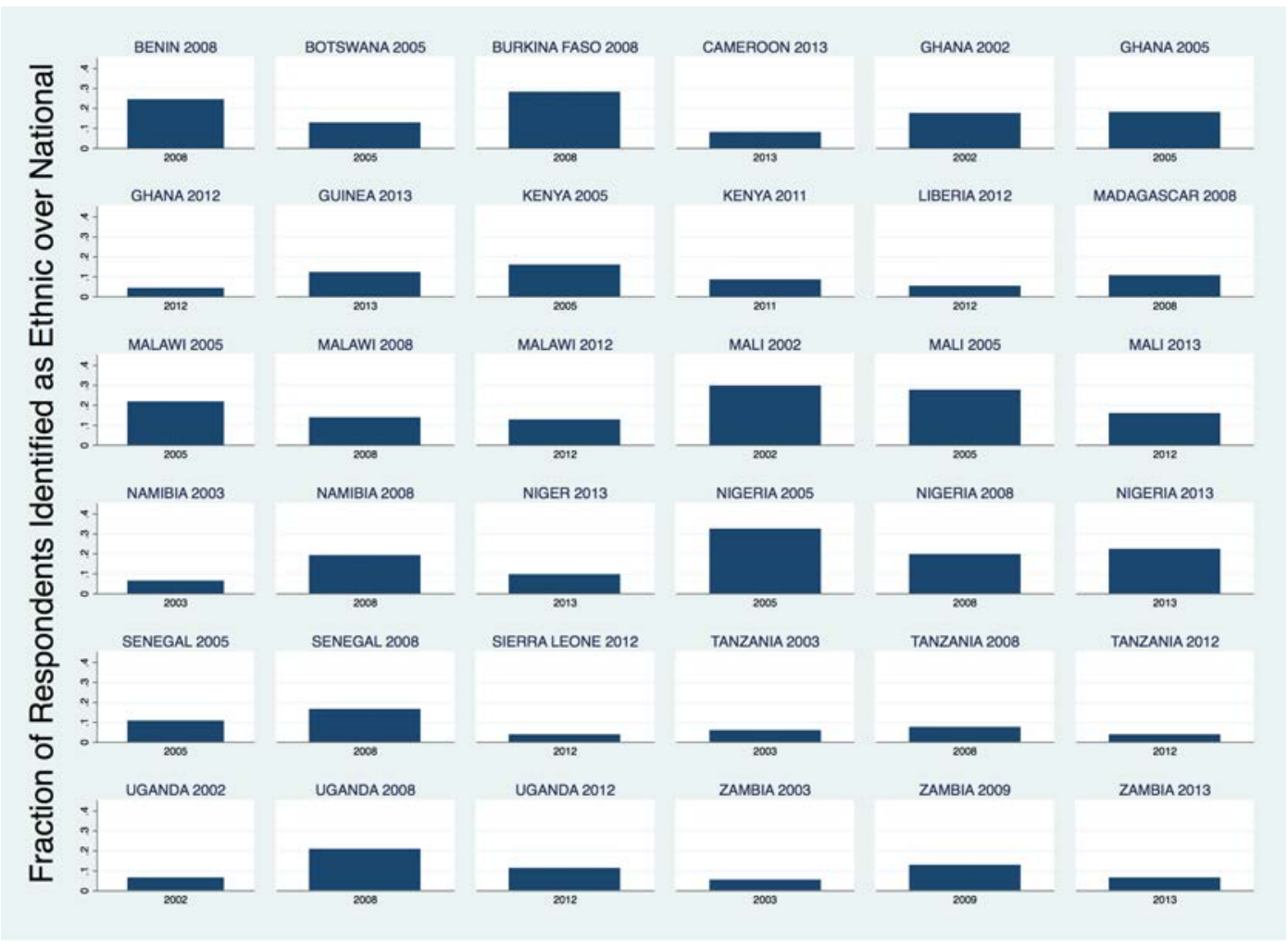

In Figure 1 we plot the share of respondents that reported stronger ethnic than national identity, separately for the sample of countries and years we exploit in our analysis. As shown, the relative strength of ethnic identity varies considerably across countries, and even in the same country over time, possibly also due to the impact of the type of major sports events we investigate. One suggestive example in this regard is given by Mali, where more than 30 percent of the individuals interviewed in 2002 emphasized ethnic over national identity, but where less than $15 \%$ did so in 2013 , when the Malian national football team achieved the third place in the Africa Cup of Nations, its best performance in the history of the competition. ${ }^{12}$ The strength of ethnic identity appears to be lower and more stable in other countries: for example in Tanzania, a country known for its effective nation-building policies (Miguel, 2004), less than $10 \%$ of respondents in any round emphasize ethnic over national identity.

To explore the impact of national team's victories on respondents' trust in others, we use four additional variables. First, we construct a measure of generalized trust computed as the

${ }^{12}$ Similarly, the typically high share of Zambians who report a strong sense of ethnic identification was greatly reduced in 2013, a year after the country's historical and unexpected victory in the 2012 ACN. Incidentally, the final took place in Libreville near the place where, twenty years earlier, most of the Zambian national football team died in an air crash, a circumstance which further strengthened the emotional valence of the victory. 
average score in four separate questions regarding trust in i) relatives, ii) other acquaintances, iii) neighbors, and iv) fellow countrymen, all defined on a 4-point scale ranging from 0 ("not at all") to 3 ("a lot"). Second, using questions on respondents' trust in people within and outside their own ethnic group, we construct measures of inter-ethnic and intra-ethnic trust, also defined over the same 4-point scale, as well as measure of inter-ethnic trust premium given by the difference between the two. ${ }^{13}$ To assess the effect of national team's victories on support for the government, we code two additional variables: trust in the ruling party (with answers ranging from 0 "not at all" to 3 'a lot") and approval of the president (with answers ranging from 1 "strongly disapprove" to 4 "strongly approve"). Finally, to examine whether victories influence respondents' overall mood, we code two measures of respondents' assessment of their current living conditions and of the country's economic situation (indicating 1 for "fairly good" and "very good", and 0 otherwise), and two measures of how they expect these conditions to evolve in the future (indicating 1 for "better" and "much better", and 0 otherwise).

\subsection{Country-Level Conflict Data}

To study the impact of national teams' victories on actual violence, in the last part of our analysis we use country-level data on conflict from the Armed Conflict Location and Event Data Project (ACLED). The data, available for the period 1997-2013, include information on the date and location of any episode of political violence - i.e., battles, killings, riots that involve either the government, rebel groups, militias, or civilians. The data also include information on the severity of the events, measured by the number of associated fatalities. Based on this information we construct three measures of conflict intensity at the countryweek level: i) a dummy for whether any conflict event occurred, ii) the number of conflict events occurred, and iii) the number of casualties associated with these events.

We also construct analogous measures specifically for ethnically-related conflict. Though the ACLED data do not explicitly distinguish between ethnic and non-ethnic conflict, some of the information in the ACLED records can be used to indirectly make this distinction. Specifically, we code as ethnically-relevant conflict events that involves the participation of actors classified as ethnic militia or whose denomination refers to an ethnic faction (e.g. "Bete Ethnic Group"), or any event for which the ACLED records include a specific reference to ethnic tensions as cause of violence. Such procedure is of course vulnerable to substantial measurement error, namely to the risk of coding as non-ethnic episodes that are in fact driven by ethnic motives. Yet, to the extent that it affects the dependent variable and is

${ }^{13}$ Because the question on inter-ethnic trust was only included in round \#3 of the Afrobarometer, the analysis on this aspect is based on a substantially smaller sample. 
unrelated to the timing of qualification, measurement error should only reduce the precision of our estimates. According to our classification, about $6 \%$ of the observations in our sample can be classified as ethnically-related (i.e., observations for which at least one ethicallyrelated conflict event occurred in a given country in a given week). Summary statistics for the different measures of conflict used in our analysis are reported in Table A.8.

\section{IndiViduAl-LEVEL ANALYSis: Ethnic IDENTIFICATION AND TRUST}

\subsection{EMPIRICAL STRATEGY}

Our empirical strategy to estimate the impact of national team's victories on individual attitudes is summarized by the following equation:

$$
\text { Outcome }_{i, e, c, t}=\alpha+\beta \text { PostVictory }_{c, t}+\gamma^{\prime} X_{i}+\Gamma_{c, t}+\Delta_{e, t}+\varepsilon_{e, t}
$$

where $i, e, c$, and $t$ denote respectively individual, language group (a proxy for ethnicity), country, and year. Outcome is one of the attitudinal variables described in the previous section; Post-Victory is the main regressor of interest and takes value 1 if the respondent was interviewed in the days after a victory of her national team in an official match, and 0 otherwise; $X_{i}$ is the vector of baseline individual controls (i.e., education, gender, age, age squared, unemployment status and an indicator for leaving in a rural area); $\Gamma$, and $\Delta$, are country $\times$ year and language group $\times$ year fixed effects, respectively; $\varepsilon_{e, t}$ is an error term which is heteroscedasticity-robust and is clustered by language group $\times$ year. Since we run our econometric model on multiple outcomes, in Tables 2 to 6 we report False Discovery Rate (FDR) adjusted p-values following Anderson (2008).

We also estimate an alternative and more demanding specification summarized by the following equation:

$$
\text { Outcome }_{i, e, c, m, t}=\alpha+\beta \text { PostVictory } y_{c, m, t}+\gamma^{\prime} X_{i}+\Theta_{c, m}+\Delta_{e, t}+\varepsilon_{e, t}
$$

where $m$ denotes the match, and $\Theta_{c, m}$ the country-match fixed effects. Hence, while when estimating equation (1) we identify the effect of Post-Victory by comparing respondents interviewed after any victory of their national team in a given year with all other respondents of the same country and language group interviewed in the same year, with equation (2) we compare respondents interviewed after a given match with others of the same country and language group interviewed before the same match.

We mainly focus on the sample of individuals interviewed in the 15 days before and after 
official matches of their national football team. ${ }^{14}$ We consider, in particular, the sample of respondents exposed to only one match, which includes over 28,000 individuals between treatment and control groups. ${ }^{15}$ For purpose of robustness, we also look at the larger sample of respondents potentially exposed to one or more matches, which includes more than 35,000 individuals. Descriptive statistics for the first sample for all variables used in our analysis are presented in Table A.1. Half of the individuals were exposed to a match in the 15 days prior to the interview; of these roughly 36 percent experienced a victory, while 44 percent and 20 percent saw their national team losing and drawing, respectively. ${ }^{16}$

Our identification strategy relies on the quasi-random nature of the date and final result of matches relative to the timing of the Afrobarometer interviews. Hence, our identifying assumption is that national teams' matches did not interfere with the implementation of the survey, or, more precisely, that victorious matches did not interfere differently than non victorious ones. Such possibility seems especially unlikely since, as emphasized by Eifert et al. (2010), the logistics involved in the implementation of the Afrobarometer survey - selection of the enumeration sites, setting up of the field teams etc. - requires many months if not years of preparation, and are hardly related to the occurrence of sports events let alone to their unpredictable result.

To assess the validity of our identification strategy, we conduct a balance test for several respondent's characteristics that may potentially correlate with the timing of the interview and the outcomes of interest. These include: gender, education, age, unemployment status, religious membership, whether the respondent belongs to the country's ethnic majority, whether (s)he lives in a rural area, and whether (s)he lives in an area where basic public goods are available. ${ }^{17}$ To control for the possibility of social desirability bias, we also test that several characteristics of the interviewer are not systematically different between treatment and control groups. These include: gender, education, whether the interviewer speaks the same language as the respondent, and whether the interviewer thought anyone influenced the re-

${ }^{14}$ The choice of this rather tight time window is to avoid having the same individual be in the treatment group for one game and in the control group for another one. We later show that our results remain virtually unchanged when replicating the analysis using a larger time window (i.e., 30 days).

${ }^{15}$ Focusing on individuals treated by just one game makes the analysis and the interpretation of the results easier, since it does not require aggregating the potentially contrasting results of subsequent games (e.g. one win followed by one loss).

${ }^{16}$ In a robustness exercise we increase the length of the time window up to 30 days before and after a match. In that case the sample size increases to nearly 44,000 .

${ }^{17}$ Evidence suggests that these characteristics can potentially affect ethnic sentiments. For instance, Robinson (forthcoming) shows that urban status, education, gender, and formal employment all positively predict national identification (relative to ethnic). Regarding age, instead, Eifert et al. (2010) find no evidence that young people are more likely to self-identify in ethnic terms. 
spondent during the interview. ${ }^{18}$ Specifically, we perform two separate balance tests: one comparing individuals interviewed before and after a match, regardless of the outcome of the match (i.e. played), and another one comparing individuals interviewed before and after a victory. To ensure that we compare respondents from the same country interviewed around the same match, we regress each variable on either treatment including country-match fixed effects, and cluster standard errors at the same level.

The results are reported in Table 1. We first show that individual characteristics are largely balanced between respondents interviewed before and after the same match (panel A). A similar pattern holds when comparing individuals interviewed before and after a victory of the national team (panel B). The only exceptions are education, gender, and rural status. Regarding the first two variables, the marginally significant differences between treatment and control group are very small: on average individuals interviewed after a victory were only 0.9 percent more likely to be men than women, and displayed lower educational attainment by just $12 \%$ of a standard deviation (or $8 \%$ of its mean value). Furthermore, the potential biases from these imbalances are likely to operate in opposite directions, since women and less educated people generally tend to display higher levels of ethnic identification (Robinson, 2014). Regarding rural status, the comparison indicate that individual in rural areas are somewhat more likely to be interviewed after a game, in general, and after a victory, in particular. As with the other variables, this imbalance should work against finding a negative effect of wins on ethnic identification, since people in rural areas are generally more likely to identify themselves with their ethnicity than people in urban areas(Robinson, 2014). ${ }^{19}$ In any event, in all the regressions presented below we control for the entire set of respondents' individual characteristics, though their inclusion does not affect our results. Finally, regardless of whether they are defined based on all matches or just victorious ones, treatment and control groups are also balanced with respect to all interviewer-related variables.

\subsection{Results: National Team's Victories AND EThNiC IDENTIFICATION}

In Table 2 we test the empirical relationship between national team's victories and ethnic identification on the baseline sample of all respondents exposed to just one match. In column 1 we regress the dummy for stronger ethnic than national identity on a dummy for being interviewed after a victory, controlling for country-year dummies. The inclusion of country-

${ }^{18}$ A large literature argues that interviewers' observable traits such as race, ethnicity, and gender can influence respondent's answers (see West and Blom (2017) for a summary). In particular, using Afrobarometer data Adida et al. (2016) find that respondents give systematically different answers to coethnic and non-coethnic interviewers.

${ }^{19}$ We find consistent patterns in our data as depicted by the coefficients on education, gender, and rural status reported in Tables 4 and A.6. 
TABle 1: BALANCE IN COVARIATES

\begin{tabular}{|c|c|c|c|c|c|}
\hline \multirow[b]{2}{*}{ Covariate } & \multirow[b]{2}{*}{$\mathrm{N}$} & \multicolumn{2}{|c|}{ Panel A: Played } & \multicolumn{2}{|c|}{ Panel B: Victory } \\
\hline & & Estimate & Std. Errors & Estimate & Std. Errors \\
\hline Male & 28758 & 0.006 & 0.004 & $0.009 *$ & 0.005 \\
\hline Education & 28758 & -0.213 & 0.134 & $-0.291^{*}$ & 0.153 \\
\hline Age & 28758 & 0.799 & 0.687 & 1.109 & 0.777 \\
\hline Unemployed & 28758 & 0.003 & 0.015 & -0.008 & 0.014 \\
\hline Major Ethnicity & 28758 & -0.024 & 0.055 & -0.028 & 0.041 \\
\hline Rural & 28758 & $0.156 * *$ & 0.070 & $0.176 * *$ & 0.083 \\
\hline Religious Group Member & 28647 & -0.025 & 0.020 & -0.020 & 0.026 \\
\hline Public Goods & 28758 & 0.007 & 0.024 & -0.021 & 0.017 \\
\hline Same Language & 28758 & -0.046 & 0.038 & -0.022 & 0.045 \\
\hline Influenced By Others & 28710 & -0.002 & 0.006 & -0.000 & 0.008 \\
\hline Male Interviewer & 28758 & -0.002 & 0.014 & -0.005 & 0.018 \\
\hline Interviewer's Education & 28728 & -0.037 & 0.052 & -0.072 & 0.062 \\
\hline Interviewer's Age & 28758 & 0.109 & 0.118 & 0.194 & 0.141 \\
\hline
\end{tabular}

$* * * \mathrm{p}<0.01, * * \mathrm{p}<0.05, * \mathrm{p}<0.1$ Robust standard errors in parentheses clustered at country-match level. Each panel presents point estimates and standard errors for 13 regressions of a covariate (listed at the left) on Played (Panel A) and Victory (Panel B). Played takes value 1 if the respondent was interviewed within 15 days after a game (regardless of the result), 0 otherwise. Victory takes value 1 if the respondent was interviewed within 15 days after a victory, 0 otherwise. All estimates are based on OLS regressions using 55 country-match dummies to ensure that the comparison in the covariates is made between respondents in the proximity of the same game and in the same country. 
year fixed effects, allows to control for all country-level confounds that vary between years, such as political or economic events (e.g., national elections, ethnic conflicts, nation-wide economic policies, yearly variation in commodity prices, etc.). The results indicate that national team's victories have a significant negative effect on the probability of self-identifying with one's own ethnicity as opposed to the country as a whole.

The coefficient becomes slightly larger and more significant in column 2, where we include the baseline set of individual controls. Results are even stronger and more significant in column 3, where we include language group $\times$ year fixed effects and cluster standard errors at the same level. The estimated effect is quite large: individuals interviewed after national team's victories are $4.4 \%$ less likely to report a strong sense of ethnic identity than other respondents of the same language group interviewed just before; this corresponds to over a $20 \%$ decrease in the average probability of ethnic self-identification.

In column 4, we include country-match fixed effects, hence restricting the comparison to fellow countrymen interviewed before and after the same victorious game of their national team. Even under this more restrictive specification the magnitude and significance of the coefficient of interest remain largely unchanged. In column 5 we examine the effect of different results of national team's matches; the results indicate that while the successful performance of the national team weakens national identity, loosing or drawing a match has no particular effect. The lack of an effect of national team's defeats is especially interesting, as it suggest that negative collective experiences do not necessarily undermine national unity. Finally, in column 6 we show that the results are qualitatively similar when estimating a nonlinear probit model instead of the linear probability model used in the previous columns. ${ }^{20}$ Next we examine how the effect on ethnic identification evolves in the days after a victory. In Figure 2 we plot the estimated coefficients and 95\% confidence intervals for dummies for 3-day periods before and after the victory. The coefficients are estimated from a unique regression in which we control for individual characteristics, country $\times$ year and language group $\times$ year fixed effects, and for the proximity to draws or defeats. ${ }^{21}$ Since we normalize the coefficient for the three days before the victory to zero, the other coefficients indicate how ethnic identification changes over time relative to the eve of the event. The figure confirms that individuals are less likely to report a strong sense of ethnic identification after a victory of the national team, and indicate that the effect persists and, if anything, becomes stronger several days after the match. In contrast, ethnic identification does not seem to evolve in any

\footnotetext{
${ }^{20}$ We obtain similar results using, as dependent variable, the original 5-point measure of ethnic identification, which, however, is not available for all rounds of the Afrobarometer. The results, both OLS and ordered probit estimates, are reported in Appendix Table A.3.

${ }^{21}$ Appendix Figure A.1 reports the coefficients obtained when including country $\times$ match instead of country $\times$ year fixed effect; the coefficients are very similar in magnitude though somewhat less precisely estimated due to the lower statistical power.
} 
TABle 2: NATional TeAm’s Victories AND Ethnic IdENTIFICATION

\begin{tabular}{|c|c|c|c|c|c|c|}
\hline & \multicolumn{6}{|c|}{ Dependent Variable: Ethnic over National Identity (0-1 dummy) } \\
\hline & (1) & (2) & (3) & (4) & (5) & (6) \\
\hline & OLS & OLS & OLS & OLS & OLS & Probit \\
\hline Post-Victory & $\begin{array}{c}-0.017 * * \\
(0.008) \\
{[0.06]}\end{array}$ & $\begin{array}{c}-0.023 * * * \\
(0.008) \\
{[0.02]}\end{array}$ & $\begin{array}{c}-0.046 * * * \\
(0.014) \\
{[0.01]}\end{array}$ & $\begin{array}{c}-0.038 * * \\
(0.015) \\
{[0.02]}\end{array}$ & $\begin{array}{c}-0.038 * * \\
(0.015) \\
{[0.02]}\end{array}$ & $\begin{array}{c}-0.177 * * * \\
(0.067) \\
-\end{array}$ \\
\hline Post-Draw & & & & & $\begin{array}{l}-0.007 \\
(0.033)\end{array}$ & \\
\hline Post-Defeat & & & & & $\begin{array}{l}-0.015 \\
(0.015)\end{array}$ & \\
\hline Country $\times$ Year FE & Yes & Yes & Yes & No & No & No \\
\hline Individual Controls & No & Yes & Yes & Yes & Yes & Yes \\
\hline Language $\times$ Year FE & No & No & Yes & Yes & Yes & Yes \\
\hline Country $\times$ Match FE & No & No & No & Yes & Yes & Yes \\
\hline Observations & 28,758 & 28,758 & 28,758 & 28,758 & 28,758 & 27,118 \\
\hline R-squared & 0.059 & 0.071 & 0.116 & 0.117 & 0.117 & - \\
\hline
\end{tabular}

$* * * \mathrm{p}<0.01, * * \mathrm{p}<0.05, * \mathrm{p}<0.1$ Robust standard errors in parentheses in columns 1 and 2 , clustered by language group $\times$ year in the other columns. False Discovery Rate (FDR) adjusted p-values are reported in square brackets (Anderson, 2008). Sample includes respondents interviewed within 15 days before and after an official game. Post-Victory, Post-Draw and Post-Defeat take value 1 if the respondent was interviewed in the 15 days after a victory, a draw or a loss respectively, and 0 otherwise. 
Figure 2: Ethnic Identity Before And After National TeAM's Victories

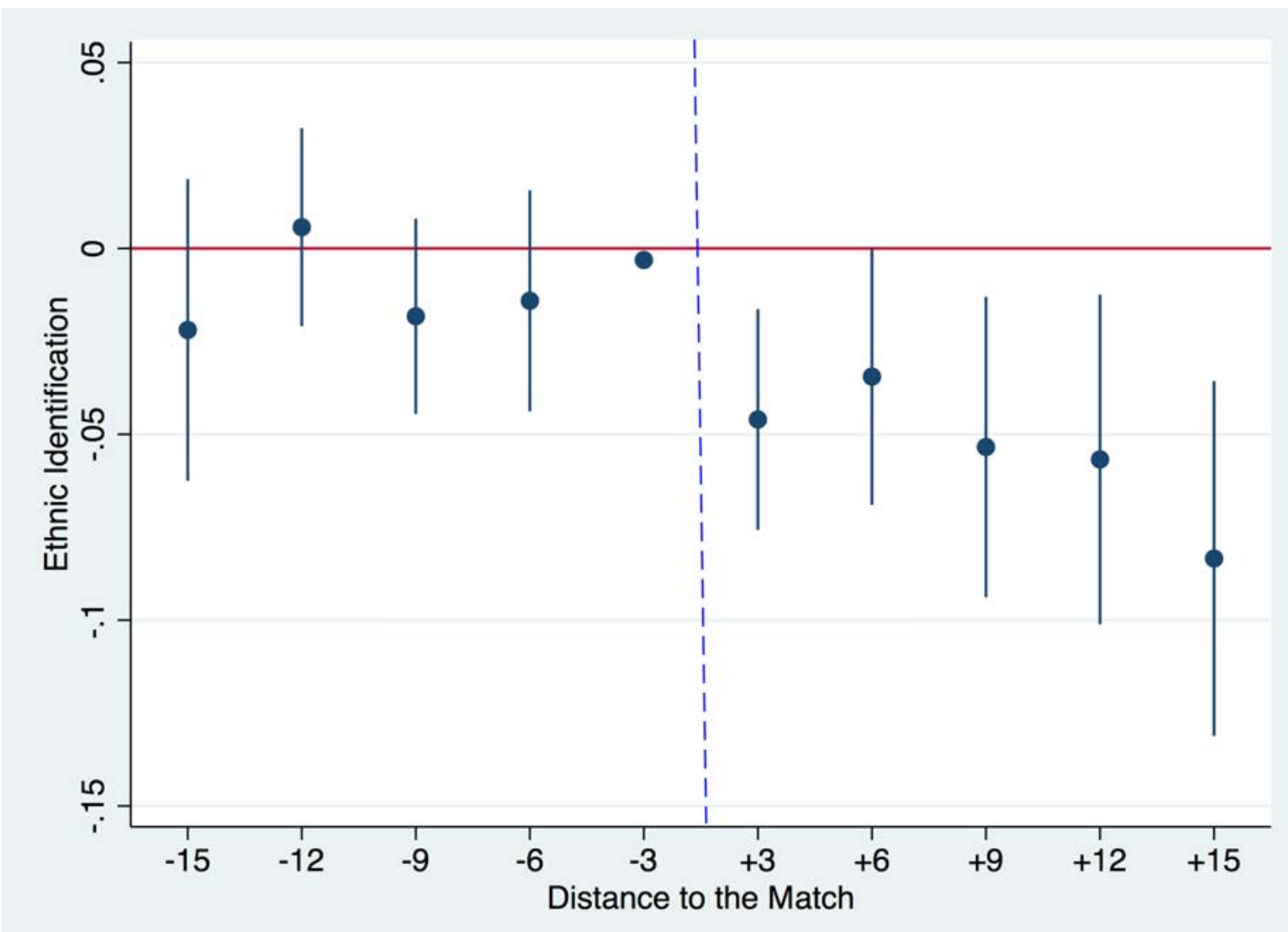

The figure plots the coefficients and the 95\% confidence intervals for nine dummies indicating 3-day blocks from 15 days before to 15 days after a victory of the national football team. The coefficient for the period between 3 to 1 days before the match is normalized to zero. Confidence intervals are based on heteroskedasticity-robust standard errors clustered by language group. The coefficients are estimated from a unique regression in which we control for individual characteristics, country $\times$ year and language group $\times$ year fixed effects, and for the proximity to draws or defeats.

particular way in the days prior to the match. ${ }^{22}$

\subsection{INTERPRETATION}

What drives the effect of national team victories on strengthening national identity? To shed light on that question, we first explore what types of victories are more likely to affect the strength of ethnic sentiments. In the first column of Table 3, we look at whether friendly

\footnotetext{
${ }^{22}$ Our baseline results - based on a 15-day time window before and after a victory - are robust to the choice of alternative time windows $(5,10,20,25$ or 30 days before and after a match) as shown in Table A.4 for the baseline specification with country $\times$ match fixed effects. The effect of national team's victories on ethnic sentiments is remarkably stable, with a somewhat larger coefficient when focusing on the days immediately before and after the match.
} 
matches affect ethnic identity, and how this compares to the impact of victories in official matches documented above. The results indicate that victories in friendly matches have virtually no effect on ethnic identification, consistent with the view that low-stakes games are less effective than high-stakes ones at spurring patriotic fervor.

We then test the hypothesis that victories against traditional rivals are more consequential than other victories. To do so, we interact our post-victory variable with an indicator of rivalry. ${ }^{23}$ The results indicate that, though all victories negatively affect ethnic identification, the effect is considerably larger for victories against traditional rivals which arguably trigger a stronger emotional reaction. This is consistent with the idea that national identity is strengthened in opposition to a salient foreign outside group.

In column 3 we focus on the heterogeneous effect of victories in matches played at home. The fact that the interaction term is not statistically significant, and that post-victory is still associated with a significant decline in ethnic identification, suggests that the effect is not driven by respondents' direct participation in the event. This underlines the imagined aspect of the shared experiences triggered by national team performance.

In column 4 we examine whether winning by a large margin boosts pride in the national team and reduces ethnic identification even further. To do so, we interact the post-victory dummy with a dummy for whether the team won by two goals or more (i.e., the top $20 \%$ of the distribution). The large and negative coefficient on the interaction term, though marginally insignificant (p-value: 0.14), provides some support for this hypothesis.

Finally, in column 5, we examine whether victories in matches in which a large number of goals were scored are associated with a larger effect. This exercise allows us to test whether our baseline effect is driven by enthusiasm for witnessing a particularly spectacular game rather than a genuine increase in national pride. We find that the interaction between the post-victory dummy and the number of total goals scored is small and insignificant, a result which provides little support for this alternative hypothesis.

We then turn attention to whether certain segments of the population are more responsive to the patriotic influence of national teams' victories. In particular, interacting the dummy Post-Victory with various individual characteristics, we test whether the effect is larger for men vs. women, for younger vs. older cohorts, for more vs. less educated individuals, and for people belonging to the largest ethnic group in the country. The results, presented in Appendix Table A.6, indicate that none of these attribute is associated with a stronger effect

\footnotetext{
${ }^{23}$ Most traditional rivalries in Sub-Saharan Africa are determined by the presence of a shared frontier or by previous conflict. The most prominent and uncontroversial ones include: Benin-Togo, Burkina Faso-Ivory Coast, Cameroon-Egypt,Cameroon-Nigeria,Cape Verde-Guinea-Bissau, Congo DR-Ghana, Congo DR-Rwanda,Ghana-Egypt,Ghana-Ivory Coast, Ghana-Congo DR, Ghana-Nigeria, Guinea-GuineaBissau, Ivory Coast-Senegal, Ivory Coast-Mali, Nigeria-Algeria, Senegal-Nigeria, South Africa-Zambia, and Zambia-Zimbabwe.
} 
TAble 3: National Team Victories and Ethnic IDENTity: Stakes, Location, Margin of Victory and Entertainment Value

\begin{tabular}{|c|c|c|c|c|c|}
\hline & \multicolumn{5}{|c|}{ Dependent Variable: Ethnic over National Identity (0-1 dummy) } \\
\hline & (1) & (2) & (3) & (4) & (5) \\
\hline Post-Victory & $\begin{array}{c}0.009 \\
(0.012) \\
{[0.55]}\end{array}$ & $\begin{array}{c}-0.032 * * \\
(0.014) \\
{[0.04]}\end{array}$ & $\begin{array}{c}-0.038 * * * \\
(0.015) \\
{[0.02]}\end{array}$ & $\begin{array}{c}-0.034 * * \\
(0.015) \\
{[0.04]}\end{array}$ & $\begin{array}{c}-0.035 * * \\
(0.016) \\
{[0.04]}\end{array}$ \\
\hline Post-Victory $\times$ Rivalry & & $\begin{array}{c}-0.095^{*} \\
(0.051)\end{array}$ & & & \\
\hline Post-Victory $\times$ Home Game & & & $\begin{array}{c}0.018 \\
(0.029)\end{array}$ & & \\
\hline Post-Victory $\times$ Wide Margin & & & & $\begin{array}{l}-0.047 \\
(0.030)\end{array}$ & \\
\hline Post-Victory $\times \#$ Goals in Game & & & & & $\begin{array}{l}-0.006 \\
(0.009)\end{array}$ \\
\hline Individual Controls & Yes & Yes & Yes & Yes & Yes \\
\hline Language FE & Yes & Yes & Yes & Yes & Yes \\
\hline Country-Match FE & Yes & Yes & Yes & Yes & Yes \\
\hline Sample: & $\begin{array}{l}\text { Friendly } \\
\text { Matches }\end{array}$ & Baseline & Baseline & Baseline & Baseline \\
\hline Observations & 28,767 & 28,758 & 28,758 & 28,758 & 28,758 \\
\hline R-squared & 0.093 & 0.117 & 0.117 & 0.117 & 0.117 \\
\hline
\end{tabular}

$* * * \mathrm{p}<0.01, * * \mathrm{p}<0.05, * \mathrm{p}<0.1$ Robust standard errors clustered at the language group level in parentheses. False Discovery Rate (FDR) adjusted p-values are reported in square brackets (Anderson, 2008). Victory takes value 1 if the respondent was interviewed within 15 days after a victory, 0 otherwise. 
of national team victories, which suggests that important sporting achievements influence the public as a whole and not just sports fans or people who are more likely to have a coethnic in the national team.

An important exception is the distinction between individuals in urban vs. rural areas. As shown in column 1 of Table 4, while we reproduce the standard finding that those in rural areas are more likely to identify with their ethnic group, the interaction with rural status displays a negative coefficient. This implies that the impact of national team victories is even stronger away from urban centers where, arguably, individuals are less likely to come into contact with people of other ethnicities. ${ }^{24}$

\footnotetext{
${ }^{24}$ On the effect of individual interaction across ethnic groups, see Boisjoly et al. (2006), Burns et al (2015), Lowe (2018), and references therein.
} 
TABle 4: Victories And EthniC IdEntificAtion: Heterogenous EFFECTS

\begin{tabular}{lccccc}
\hline \hline & \multicolumn{4}{c}{ Dependent Variable: Ethnic over National Identity $(0-1$ dummy) } \\
\cline { 2 - 6 } & $(1)$ & $(2)$ & $(3)$ & $(4)$ & $(5)$ \\
\hline \multirow{2}{*}{ Post-Victory } & $-0.045^{* * *}$ & $-0.036^{* *}$ & $-0.034^{* *}$ & $-0.036^{* * *}$ & $-0.054^{* * *}$ \\
& $(0.014)$ & $(0.014)$ & $(0.014)$ & $(0.013)$ & $(0.014)$ \\
& {$[0.01]$} & {$[0.03]$} & {$[0.03]$} & {$[0.02]$} & {$[0.01]$} \\
Interaction & $-0.026^{*}$ & $0.057^{* *}$ & $-0.332^{* *}$ & $-0.277^{* *}$ & $-0.321^{*}$ \\
& $(0.015)$ & $(0.028)$ & $(0.166)$ & $(0.126)$ & $(0.191)$ \\
Uninteracted Term & $0.022^{* * *}$ & $-0.025^{* *}$ & & & \\
& $(0.012)$ & $(0.013)$ & - & - & - \\
Interaction Term & Rural & State & Share & National & Team \\
Country $\times$ Match FE & Yes & Yes & Yes & Yes & Yes \\
Individual Controls & Yes & Yes & Yes & Yes & Yes \\
Language $\times$ Year FE & Yes & Yes & Yes & Yes & Yes \\
\hline Observations & 28,758 & 25,478 & 28,758 & 28,758 & 24,271 \\
R-squared & 0.116 & 0.117 & 0.113 & 0.119 & 0.153 \\
\hline \hline
\end{tabular}

$* * * \mathrm{p}<0.01, * * \mathrm{p}<0.05, * \mathrm{p}<0.1$ Robust standard errors clustered at the language group $r \times$ year level in parentheses. False Discovery Rate (FDR) adjusted p-values are reported in square brackets (Anderson, 2008). Post-Victory takes value 1 if the respondent was interviewed in the 15 days after a victory, 0 otherwise. To ease the comparison with previous tables, variables in the interaction terms were demeaned. State presence is computed as the mean value of three indicators coded by Afrobarometer's interviewer at the enumeration area: presence of schools, post offices, and paved roads. Share of ethnic ID is the proportion of individuals with strong ethnic identification before a match in given country. National diversity is based in the ELF index from Fearon and Laitin (2003). Team diversity is computed as a ELF index based in the ethnic composition of the national team in the same year of the Afrobarometer's wave.

To further investigate the link between these results and nation-building, we examine how the effect of national team victories depends on the presence of the state at the local level. We use the availability of basic public goods as a proxy for state presence since poor public good provision may arguably generate a sense of disconnect from the rest of the nation. Specifically, we use information from the Afrobarometer surveys regarding the presence of public schools, post offices, and paved roads in the area where the respondent is located, and consider the average of these three indicators.

As shown in column 2 of Table 4, state presence is, unsurprisingly, associated with reduced ethnic sentiment in general. However, state presence also dampens the impact of national team victories in reinforcing national identity over ethnic allegiances. This result is sugges- 
tive of how different forms of nation building might interact with each other. The indicators that we include in our measure are very much the sort of public goods that are often seen as vehicles for nation building: inculcation via schooling, as well as easier connection with the rest of the country. In our context, these seem to operate as substitutes for the impact of shared experiences: perhaps there is less scope for further reinforcing national identity where that is stronger to begin with, through other means.

We further test this idea by looking at how the effect of national team victories varies according to the strength of ethnic identification at the national level. Column 3 indicates that the effect is indeed stronger when a larger share of the country's respondents identify with their ethnic group. Similarly, more ethnic diversity at the national level, as measured by the Fearon and Laitin (2003) ELF index, is also associated with a bigger impact, as shown in column 4.

Last but certainly not least, we ask wether the impact of national team performance may be related to a "role modeling" effect: the idea that showcasing how different groups can cooperate to achieve success against a common foreign adversary. For that we use the data we collected on the ethnic composition of the national team rosters. ${ }^{25}$ Column 5 in Table 4 shows that greater team diversity is associated with a stronger impact of national team victories.

In sum, the heterogeneity analysis indicates that shared experiences help build national identity in specific ways that are most effective in environments where other nation building strategies are less so.

\subsection{National Team's Victories AND Inter-Ethnic Trust}

We next turn to the question of whether national teams' victories also affect individual propensity to trust others, particularly people from other ethnicities. First, we look at the effect of victories on trust towards other people in general. In column 1 of Table 5 we estimate our baseline specification with country $\times$ match fixed effects using generalized trust as the dependent variable. The result indicate that, following a victory of the national team, individuals tend to generally trust others more. In column 2 we test whether this effect is stronger for inter-ethnic trust, using as dependent variable the self-reported measure of trust in people of other ethnic groups. Again the coefficient on Post-Victory is negative and significant; furthermore, it is larger than the one for generalized trust, which suggests a stronger effect on trust outside one own ethnicity. The estimated coefficient is economically meaningful since its represents an increase in trust equivalent to one fifth of its mean value in our

${ }^{25}$ In Table A.7 we report the list of all the team-years for which we were able to collect information on players' ethnicity. 
TABle 5: NATiOnAl TeAM’s Victories AND TRUst in Others

\begin{tabular}{lccc}
\hline \hline & $(1)$ & $(2)$ & $(3)$ \\
\hline & $\begin{array}{c}\text { Generalized } \\
\text { Trust }\end{array}$ & $\begin{array}{c}\text { Inter-Ethnic } \\
\text { Trust }\end{array}$ & $\begin{array}{c}\text { Inter-Ethnic } \\
\text { Trust Premium }\end{array}$ \\
\hline Post-Victory & $0.099^{* * *}$ & $0.228^{* *}$ & $0.056^{*}$ \\
& $(0.031)$ & $(0.105)$ & $(0.029)$ \\
& {$[0.01]$} & {$[0.04]$} & {$[0.07]$} \\
Country $\times$ Match FE & Yes & Yes & Yes \\
Individual Controls & Yes & Yes & Yes \\
Language $\times$ Year FE & Yes & Yes & Yes \\
\hline Observations & 25,475 & 7,992 & 7,979 \\
R-squared & 0.244 & 0.195 & 0.056 \\
\hline \hline
\end{tabular}

$* * * \mathrm{p}<0.01, * * \mathrm{p}<0.05, * \mathrm{p}<0.1$. Robust standard errors clustered at the language group $\times$ Year level in parentheses. False Discovery Rate (FDR) adjusted p-values are reported in square brackets (Anderson, 2008). Post-Victory takes value 1 if the respondent was interviewed in the 15 days after a victory, 0 otherwise. Generalized trust is the average level of trust in relatives, other acquaintances, other countrymen, and neighbors. Interethnic trust is the self-reported score of trust in people of other ethnicities, while Interethnic premium is the difference between the latter and trust in co-ethnics.

sample. ${ }^{26}$ To further test for the larger effect on trust across rather than within ethnic groups, in column 3 we use as dependent variable a measure of inter-ethnic trust premium, given by the difference between trust outside and within one's own ethnic group. Consistent with the previous findings, national teams victories' improve respondents' relative propensity to trust people of other ethnicities.

\subsection{NATional TeAM's Victories And Other AtTitudes}

An important question is whether weaker ethnic identity and higher inter-ethnic trust reflect a genuine change in attitudes or, rather, a generally euphoric mood due to national team's achievements. One way to test this hypothesis is to examine whether victories are also associated with changes in other attitudes unrelated to ethnic sentiments. We perform this exercise in Table 6. In column 1 we start by assessing whether national team's victories are

\footnotetext{
${ }^{26}$ The implied standardized beta coefficient is 0.05 . This effect is quite large compared to other determinants of trust examined in the literature. For example, it corresponds to more than half the long-term effect of historical exposure to slave trade on inter-ethnic trust estimated by Nunn and Wantchekon (2011).
} 
associated with an increase in respondents' trust in the ruling party. ${ }^{27}$ When estimating our most complete specification we find that Post-Victory has no significant effect on the outcome of interest. A similar pattern emerges in column 2 when we use as dependent variable the respondent's approval rate for the president. These results indicate that football-driven patriotic shocks do not necessarily translate into generally more positive political attitudes and into higher support for incumbent rulers.

To further rule out that the effect of national team victories is driven by general euphoria, we test whether victories affect respondents perception of the country's and of their own economic situation and prospects. In column 3 and 4 we estimate our baseline specification using as dependent variable dummies for whether a respondent reports having a positive assessment of the country's current economic conditions, and positive expectations of whether they will improve in the near future, respectively. In column 5 and 6 we do the same using as dependent variables dummies for whether a respondent has a positive assessment of her own living conditions, and expects these to improve in the future. The lack of significant coefficients in any column further corroborates the view that football-driven patriotism does not make individual more optimistic in general, and does not alter their perception of the conditions they live in.

All the results presented so far are based on the sample of individuals exposed to just one game. In Appendix Table A.5, we replicate the results on the larger sample of individuals who, in the days prior to the interview, may have experienced more than one match of their national team, which is rather common in the case of back-to-back matches. In this case, the treatment is less clear-cut since a team may have contrasting results in different matches (e.g. win one but loose another one). To address this issue we use as main regressor of interest either the share of all matches won or the share of available points won (with a win corresponding to 3 points, a draw to 1 , and a loss to 0 ). The results confirm that a more successful performance by the national team is associated with a reduction in the strength of ethnic identification, and an increase in generalized and inter-ethnic trust, while there is no effect on other opinions or expectations.

\section{Country-Level Analysis}

\subsection{EMPIRICAL STRATEGY}

The results presented so far indicate that football-driven positive shocks contribute to reducing ethnic identification and inter-ethnic mistrust. An important related question is whether

${ }^{27}$ Evidence that sports victories, and the resulting euphoria, can boost support for the incumbent is available, for example, from Healy et al. (2010) who find that victories in US college football games lead to an increase in the incumbent's vote share in Senate, gubernatorial, and presidential elections. 
TABle 6: National Team's Victories And Other AtTitudes

\begin{tabular}{lcccccc}
\hline \hline & $(1)$ & $(2)$ & $(3)$ & $(4)$ & $(5)$ & $(6)$ \\
& Trust in & President's & \multicolumn{2}{c}{ Assess Country's } & \multicolumn{2}{c}{ Assess Own } \\
& Ruling Party & Approval & Economic Conditions & \multicolumn{2}{c}{ Living Conditions } \\
& & & Present & Future & Present & Future \\
\hline Post-Victory & -0.006 & -0.005 & -0.020 & -0.004 & -0.010 & -0.032 \\
& $(0.033)$ & $(0.034)$ & $(0.019)$ & $(0.020)$ & $(0.017)$ & $(0.022)$ \\
& {$[0.88]$} & {$[0.88]$} & {$[0.34]$} & {$[0.88]$} & {$[0.59]$} & {$[0.18]$} \\
\hline Country $\times$ Match FE & Yes & Yes & Yes & Yes & Yes & Yes \\
Individual Controls & Yes & Yes & Yes & Yes & Yes & Yes \\
Language $\times$ Year FE & Yes & Yes & Yes & Yes & Yes & Yes \\
\hline Observations & 27,270 & 27,330 & 28,752 & 28,746 & 28,725 & 28,733 \\
R-squared & 0.186 & 0.241 & 0.121 & 0.160 & 0.125 & 0.162 \\
\hline \hline
\end{tabular}

$* * * \mathrm{p}<0.01, * * \mathrm{p}<0.05, * \mathrm{p}<0.1$ Robust standard errors clustered at the language group $\times$ year level in parentheses. False Discovery Rate (FDR) adjusted p-values are reported in square brackets (Anderson, 2008).PostVictory takes value 1 if the respondent was interviewed in the 15 days after a victory, 0 otherwise. Trust in Ruling Party is a dummy variable that takes value 1 if the respondent reports trusting the ruling party (either "somewhat" or a "lot") and 0 otherwise. President's Approval is a dummy that takes value 1 if the respondent reports approving the president's performance in the previous 12 months (either "approve" or "strongly approve") and 0 otherwise. The other dependent variables are dummies for whether the respondent's has a positive assessment of the current economic conditions of her own living conditions respectively ("good" or "very good"), or positive expectations about the evolution of the country's and of their own conditions in the future respectively (“better" or "much better"). 
the documented attitudinal change may contribute to decrease actual violence, and how longlasting this effect may be. To shed light on this issue we analyze how civil conflict in SubSaharan African countries evolves following important achievements of the national football teams.

Specifically, we attempt to exploit quasi-experimental variation in whether a team qualified for the tournament phase of the African Cup of Nations (ACN), the most important continental competition for African national teams which generates widespread popular attention. The ACN involves two phases: i) a qualifying stage in which all teams compete, and ii) a final (or tournament) stage in which only the teams that ranked highest in the qualifying round compete for the title. In the qualifying round teams are divided into groups, each teams plays each of the others twice (one at home and one away) with each match assigning a certain number of points, and the team(s) with more points (usually one or two) qualify to the final round. The qualifying stage is usually very competitive, and qualification is often decided only in the last match day based on just a narrow point margin or goal difference. Our strategy consists in i) identifying teams in the same group that, until the last match day of the group stage, were both in the position to qualify, but one of which barely did while the other did not, and ii) compare the evolution of conflict in the two countries in the six months before and after the qualification. ${ }^{28}$

Our identification strategy is summarized by the following equation:

$$
\operatorname{Conf}_{c, q, t}=\alpha+\beta \text { Qual }_{c, q, t}+\sum_{k=1}^{4} \delta^{k} \operatorname{Conf}_{c, q, t-k}+\sum_{t=-25}^{25} \Gamma_{t}+\Delta_{c, q}+\varepsilon_{c, q}
$$

where $c, q$, and $t$ denote country, qualification, and week to and since qualification (-25 to $+25)$. Conf is one of the three measures of conflict intensity described above. Qual, our regressor of interest, is a dummy variable that equals 1 for countries of teams that qualified only in the weeks after qualification, and 0 otherwise. $\sum_{t=-25}^{25} \Gamma_{t}$ is a set of dummies for each of the weeks before and after the qualification, while $\Delta_{c, q}$ are country $\times$ qualification fixed effects. To control for possible auto correlation in conflict events, we also control for the occurrence of conflict in the previous weeks (up to four). Heteroscedasticity-robust standard errors are clustered by country $\times$ qualifier.

\footnotetext{
${ }^{28}$ Qualification to the FIFA World Cup provides a similar experiment, but poses challenges regarding the definition of control and treatment groups (e.g. Angola barely qualified to the ACN in 1997, while barely missing out in the WC in the same year) and adds relatively little variation. This is because there are few WC spots for African countries, and most of those are typically taken by a very small number of historically strong teams, many of which are from North Africa. In any case, we will show our results are robust to including WC qualifiers into the sample.
} 
Figure 3: Example of Close Qualification: Group A, ACN 2012

\begin{tabular}{|c|c|c|c|c|c|c|c|c|}
\hline Team & PId & W & D & L & GF & GA & GD & Pts \\
\hline Mali & 5 & 3 & 0 & 2 & 7 & 4 & 3 & $\mathbf{9}$ \\
\hline Zimbabwe & 5 & 2 & 2 & 1 & 6 & 3 & 3 & $\mathbf{8}$ \\
\hline Cape Verde & 5 & 2 & 1 & 2 & 5 & 6 & -1 & $\mathbf{7}$ \\
\hline Liberia & 5 & 1 & 1 & 3 & 5 & 10 & -5 & $\mathbf{4}$ \\
\hline
\end{tabular}

\begin{tabular}{|cccc|}
\hline $08 / 10 / 2011$ & Liberia & $2-2$ & Mali \\
& Cape Verde & $2-1$ & $\equiv$ Zimbabwe \\
\hline
\end{tabular}

\begin{tabular}{|c|c|c|c|c|c|c|c|c|}
\hline Team & PId & W & D & L & GF & GA & GD & Pts \\
\hline Mali & 6 & 3 & 1 & 2 & 9 & 6 & 3 & $\mathbf{1 0}$ \\
\hline Cape Verde & 6 & 3 & 1 & 2 & 7 & 7 & 0 & $\mathbf{1 0}$ \\
\hline Zimbabwe & 6 & 2 & 2 & 2 & 7 & 5 & 2 & $\mathbf{8}$ \\
\hline Liberia & 6 & 1 & 2 & 3 & 7 & 12 & -5 & $\mathbf{5}$ \\
\hline
\end{tabular}

\subsection{QuAlification to ACN AND Social Conflict}

For our analysis we use data from ACLED on the occurrence and severity of violent conflict events in Sub-Saharan African countries between 1997 and 2013, with a particular focus on the months before and after each ACN qualification campaign. As mentioned above, our key comparison is between countries that barely qualified to the ACN finals (our treatment group) and those that did not (our control group). The underlying identification assumption is that if two teams in the same group got to the last match day with concrete chances of qualifying, which one would actually qualify will be determined by quasi-random circumstances, such as a goal scored in the final minutes of the last match by one side or the other. One example of such scenario, depicted in Figure 3, is available from 2012, when three teams in qualifying group A, Mali, Zimbabwe, and Cape Verde, were in position to qualify until the last match day while only one team, Liberia, was already eliminated. In the last two matches while Cape Verde defeated Zimbabwe, Mali was not able to beat Liberia but still managed to qualify due to a one-goal difference. In this case Mali would be included in the treatment group while both Cape Verde and Zimbabwe in the control group.

Table A.9 reports the countries included in the control and treatment group (46 and 55 respectively) for each qualifying campaign. In Table A.10 we test whether the countries in the two groups are balanced along a range of characteristics that may affect conflict. We focus in particular on the following variables, measured in the year prior to qualification: GDP per capita, poverty rate, income inequality, life expectancy, population density, share of urban population, political corruption index of political, and autocracy index, as well as two mea- 
sures of past conflict intensity, i.e., the number of active conflicts, and a dummy for whether the country experienced a civil war in the 1990s. ${ }^{29}$ In column 1 and 2 we report the mean for each variable separately for treatment and control group, and in column 3 the p-value for the difference. The only two variables that are somewhat unbalanced (differences significant at the $10 \%$ level) are autocracy and political corruption, which are both somewhat higher for treatment than for control countries. The differences are however rather small corresponding to respectively a third and a fourth of a standard deviation on the sample of Sub-Saharan African countries for the period of interests. In column 4 we test whether covariates are balanced between countries that did and did not qualify in the same qualifying campaign; to this end, we report the coefficients from separate OLS regressions of each covariate on our treatment variable and on a set of nine qualification campaign dummies. The results indicate that the difference is insignificant for all but three variables: political corruption, autocracy, and poverty rates. Yet, in our empirical analysis we control for country $\times$ qualifier fixed effects which capture all observable and unobservable factors specific to a country in a given year that may affect conflict.

To further corroborate our identification strategy, we also test that conflict was not evolving differently in the treatment and in the control group prior to qualification, a situation that would threaten our Diff-in-Diff approach. To do so, we estimate a variant of equation 3 pooling observations for treatment and control groups and assigning a fictitious treatment for the pre-qualification period to countries that will eventually qualify. Specifically, this variable takes value 1 for the 12 weeks prior to qualification and 0 otherwise. If conflict was evolving differently in the two groups in the pre-qualification period, we would expect the fictitious treatment to display a significant coefficient. The results, reported in Table 7 , seem to rule out this possibility: regardless of what measure of conflict is used and whether we control for conflict in previous weeks, we find no evidence that conflict was evolving differently in the three month pre-qualification in countries that would eventually qualify relative to countries that would not.

\subsection{QUALIFICATION TO ACN AND CONFLICT}

In Table 8 we examine the effect of national teams' (close) qualification on conflict prevalence and intensity. We start by estimating, in column 1, our baseline specification with country $\times$ qualifying campaign and week fixed effects (equation 3 ), using as dependent vari-

\footnotetext{
${ }^{29}$ Data on GDP, poverty rates, income inequality, life expectancy, population density, and share of urban population are from the 2017 version of the World Development Indicators (2017); data on political corruption are from Varieties of Democracy (V-Dem, v6.2); data on autocracy index are from the Polity IV project; data on civil conflicts in 1990s are fromFearon and Laitin (2003); the indicator of active conflict is constructed based on the UCDP PRIO Conflict dataset.
} 
TABle 7: PARAllel TRends Test

\begin{tabular}{lcccccc}
\hline \hline & $(1)$ & $(2)$ & $(3)$ & $(4)$ & $(5)$ & $(6)$ \\
\hline Dependent Variable: & \multicolumn{2}{c}{$\begin{array}{c}\text { Dummy for } \\
\text { Any Conflict }\end{array}$} & \multicolumn{2}{c}{$\begin{array}{c}\text { Number of } \\
\text { Events }\end{array}$} & $\begin{array}{c}\text { Number of } \\
\text { Fatalities }\end{array}$ \\
& 0.036 & 0.040 & 0.048 & 0.040 & -0.107 & -0.103 \\
\hline \multirow{2}{*}{12 Weeks Before Qualification } & $(0.038)$ & $(0.037)$ & $(0.067)$ & $(0.056)$ & $(0.104)$ & $(0.081)$ \\
\hline Country $\times$ Qualifier FE & Yes & Yes & Yes & Yes & Yes & Yes \\
Week FE & Yes & Yes & Yes & Yes & Yes & Yes \\
4 Lags of Conflict & No & Yes & No & Yes & No & Yes \\
\hline Observations & 2,525 & 2,121 & 2,525 & 2,121 & 2,525 & 2,121 \\
R-squared & 0.010 & 0.023 & 0.008 & 0.040 & 0.008 & 0.033 \\
\hline \hline
\end{tabular}

$* * * \mathrm{p}<0.01, * * \mathrm{p}<0.05, * \mathrm{p}<0.1$ Robust standard errors in parentheses clustered at the country $\times$ qualifier level. Sample covers 25 weeks before the end of qualification process (i.e. pre-treatment period). The variable 12 Weeks Before Qualification takes value 1 during the 12 weeks immediately before the end of the qualification process for the countries that will eventually qualify to the $\mathrm{ACN}, 0$ otherwise. Conflict data comes from the ACLED dataset.

able a dummy for whether any conflict event occurred in the country in a given week. The results indicate that the probability of experiencing conflict is significantly lower in the months following the qualification; the effect is sizable corresponding to a $9 \%$ decrease in the probability of conflict in a given week. The effect remains largely unchanged in column 2 where we control for conflict in each of the previous four weeks. ${ }^{30}$ The results are qualitatively similar in columns 3 and 4 when we use the two measures of conflict intensity, i.e., (log+1 of) the number of conflict events occurred, and ( $\log +1$ of) the number of fatalities associated with them, respectively. The effect is economically sizable: countries whose teams barely qualified experience a reduction of $18 \%$ in the number of conflict episodes and of 20-23 $\%$ in the number of fatalities relative to countries whose teams barely did not. The table also reports the long-run impact of the qualification, which takes into account the effect of a reduction in today's conflict on future violence. As reported in Table A.12, we obtain analogous results using the number of conflict episodes and the number of victims as dependent variables (rather than the $\log$ ) and estimating maximum likelihood negative binomial regressions.

${ }^{30}$ The results are virtually the same if we include the four lags of conflict occurrence one by one or in any combination. Also they are very similar when estimating a Probit model rather than a linear probability model (results shown in Table A.11). 
TABLE 8: IMPACT OF ACN QUALIFICATION ON CONFLICT

\begin{tabular}{|c|c|c|c|c|}
\hline & (1) & (2) & (3) & (4) \\
\hline & $\begin{array}{l}\text { Conflict } \\
\text { Dummy }\end{array}$ & $\begin{array}{l}\text { Conflict } \\
\text { Dummy }\end{array}$ & $\begin{array}{c}\text { Number of } \\
\text { Events }(\log +1)\end{array}$ & $\begin{array}{c}\text { Number of } \\
\text { Fatalities }(\log +1)\end{array}$ \\
\hline Post-Qualification & $\begin{array}{c}-0.078 * * \\
(0.031)\end{array}$ & $\begin{array}{c}-0.068 * * \\
(0.026)\end{array}$ & $\begin{array}{c}-0.105 * * * \\
(0.038)\end{array}$ & $\begin{array}{c}-0.147 * * \\
(0.058)\end{array}$ \\
\hline Conflict variable $_{t-1}$ & & $\begin{array}{l}0.112 * * * \\
(0.021)\end{array}$ & $\begin{array}{l}0.261 * * * \\
(0.024)\end{array}$ & $\begin{array}{c}0.163 * * * \\
(0.032)\end{array}$ \\
\hline Conflict variable $_{t-2}$ & & $\begin{array}{c}0.012 \\
(0.019)\end{array}$ & $\begin{array}{c}0.069 * * * \\
(0.026)\end{array}$ & $\begin{array}{l}0.129 * * * \\
(0.024)\end{array}$ \\
\hline Conflict variable $_{t-3}$ & & $\begin{array}{c}0.023 \\
(0.017)\end{array}$ & $\begin{array}{l}0.041 * \\
(0.021)\end{array}$ & $\begin{array}{l}0.051 * * \\
(0.021)\end{array}$ \\
\hline Conflict variable $_{t-4}$ & & $\begin{array}{c}0.009 \\
(0.018)\end{array}$ & $\begin{array}{c}0.076 * * * \\
(0.020)\end{array}$ & $\begin{array}{l}-0.018 \\
(0.032)\end{array}$ \\
\hline Long-Run Impact & -0.078 & -0.081 & -0.190 & -0.218 \\
\hline Country $\times$ Qualifier FE & Yes & Yes & Yes & Yes \\
\hline Week FE & Yes & Yes & Yes & Yes \\
\hline Observations & 5,050 & 4,646 & 4,646 & 4,646 \\
\hline R-squared & 0.010 & 0.024 & 0.118 & 0.070 \\
\hline
\end{tabular}

The sample includes the 25 weeks before and after the close qualification for 101 country $\times$ qualifier pairs. The variable Post-Qualification takes value 1 for the team that qualified for the weeks after the qualification and 0 otherwise. The dependent variables are respectively a dummy for whether any conflict event was recorded in the country in a given week (columns 1 and 2), the $\log (+1)$ of the number of conflict events recorded in a given week (column 3), and the $\log (+1)$ of the number of fatalities associated with those events (column 4). All conflict data are from the ACLED dataset. *** $\mathrm{p}<0.01,{ }^{* *} \mathrm{p}<0.05,{ }^{*} \mathrm{p}<0.1$. Robust standard errors clustered by country $\times$ qualifier reported in parentheses. 
In Figure 2 we provide additional graphical evidence of the impact of qualification on conflict and examine the duration of this effect. To this end, we plot the estimated coefficients and $95 \%$ confidence intervals of the interaction terms between the treatment variable and dummies for eleven four-week periods in the months before and after the qualification. The coefficients are obtained from a regression which also include 50 week dummies and 101 country $\times$ qualifier dummies. To facilitate the interpretation of the results, we normalize to 0 the coefficient on the four-week periods immediately before qualification.

The results indicate clearly that the occurrence and the number of conflict events (top and bottom panel respectively) decrease sharply in the weeks following the qualification to the $\mathrm{ACN}$ tournament. Indeed, all the coefficient for the post-qualification periods are significantly different than 0 at the $10 \%$ level and most of them at the $5 \%$ level. Two additional patterns emerge quite clearly. First, none of the coefficients for the periods before qualification is significantly different than zero, confirming the absence of any differential trend in countries that would later qualify. Second, the effect of qualification on conflict persists and, if anything, becomes stronger as more time elapses since qualification, especially three months after it.

To further test the persistence of the effect in Table 9, we re-estimate our diff-in-diff specification splitting the post-qualification period in two sub-periods: the first 12 weeks after qualification, and the following 13 weeks. The results document a reduction in conflict occurrence and intensity of a similar magnitude for the two periods; in fact, the point estimates for the second period are somewhat larger and more significant when using the dummy and the number of events as dependent variables (columns 1-4), but slightly smaller for the number of fatalities (columns 5-6). Results are largely similar when controlling for the lags of conflict (columns 2, 4, and 6). Combined with the results on attitudes, these findings provide robust evidence that, by priming a sentiment of national unity and by alleviating inter-ethnic cleavages, important achievements of the national team can contribute to reduce violence in a tangible and rather persistent way.

\subsection{EFFECT OF QuAlification on CONFLict: Heterogeneity}

We then examine whether unexpected qualifications have a stronger effect on conflict. Indeed, it seems plausible that qualification to the ACN tournament may be perceived as an especially important achievement for teams that never qualified in the past or that had not qualified in a long time, as opposed to teams that usually do. This would be in line with previous findings on the effect of sports results on violence and crime which indicate that unexpected outcomes are more consequential than expected ones (Card and Dahl, 2011; Munyo and Rossi, 2013). 


\section{Figure 4: OCCURRENCE OF CONFLICT AND NuMBER OF CONFLICT EPISOdES BEFORE AND AFTER QUALIFICATION}

Figure A: OCCURRENCE OF CONFLICT (4-WEeK BANDWIDTHS)

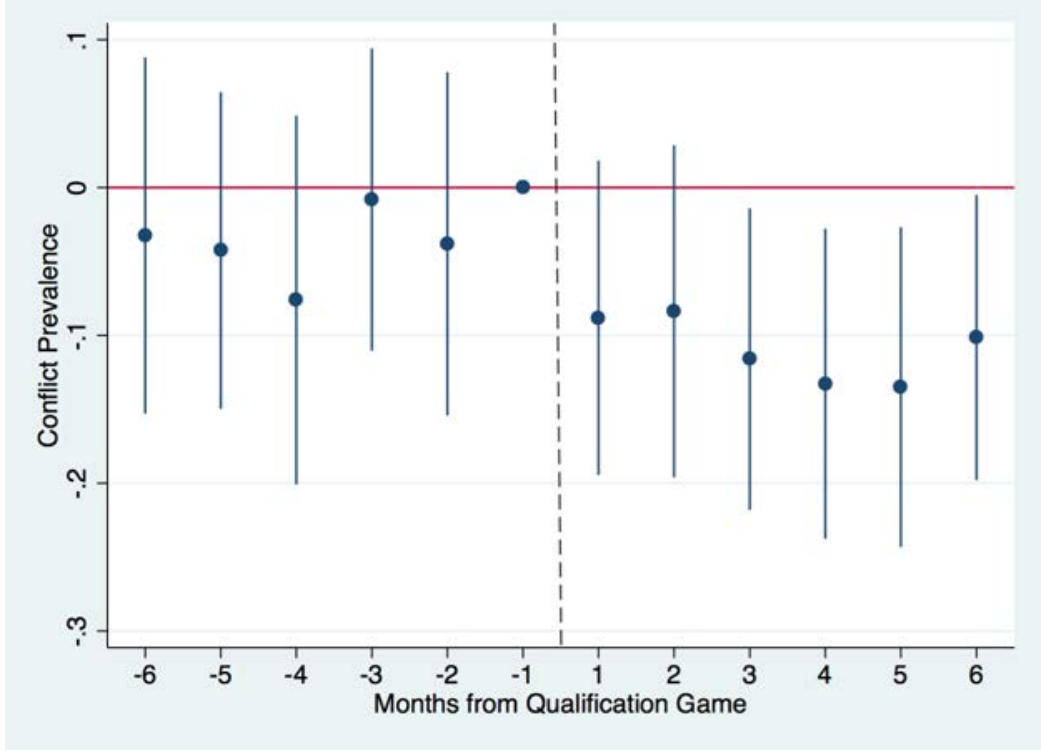

Figure B: Number of CONFLict EPISOdes (4-WeEk BANDWIDTHS)

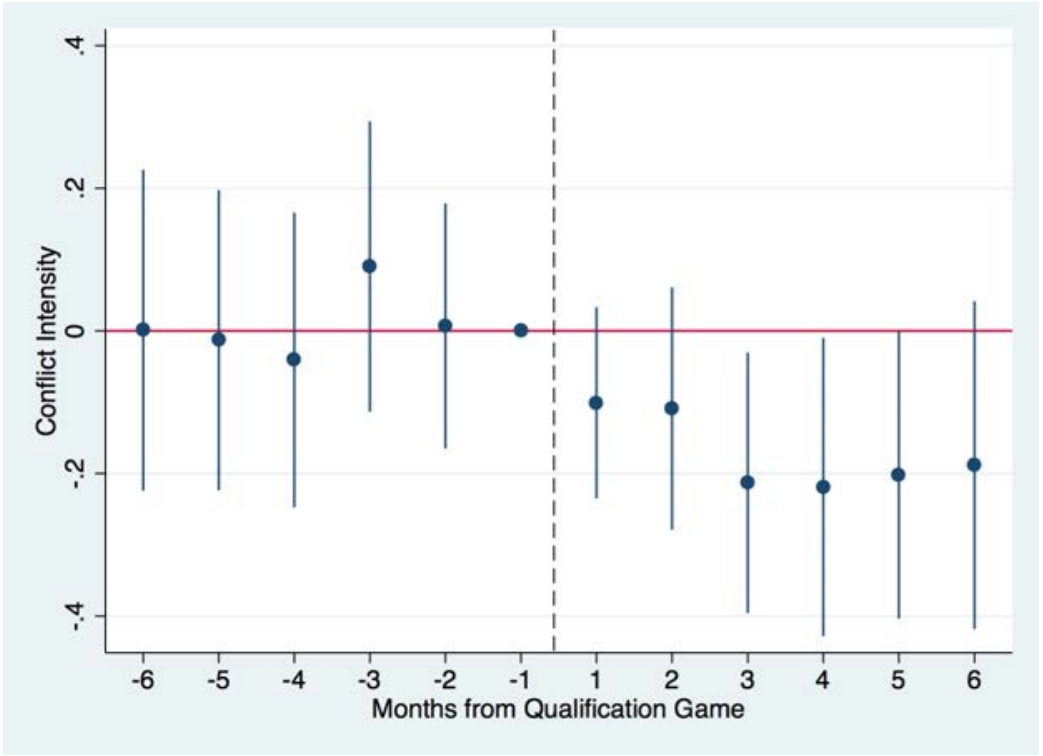

Figures plot coefficients and 95\% confidence intervals for interactions between the dummy for countries that barely qualified to the ACN and 11 dummies for 4-week period included between 25 weeks before and after the qualification. The coefficient for the 4 weeks immediately before the qualification is normalized to zero. The dependent variable for the top panel is a dummy for whether any conflict event has been recorded in the country in the week, while for the bottom panel is $(\log +1)$ the number of conflict events recorded in the country in the week. The regressions also include week and country $\times$ qualifier dummies. Confidence intervals are based on heteroskedasticity-robust standard errors clustered by country $\times$ qualifier. 
Table 9: Evolution of Conflict After Qualification

\begin{tabular}{lcccccc}
\hline \hline & $(1)$ & $(2)$ & $(3)$ & $(4)$ & $(5)$ & $(6)$ \\
\hline \multirow{2}{*}{ Dependent Variable: } & \multicolumn{2}{c}{$\begin{array}{c}\text { Conflict } \\
\text { Dummy }\end{array}$} & $\begin{array}{c}\text { Number of } \\
\text { Events }(\log +1)\end{array}$ & \multicolumn{2}{c}{$\begin{array}{c}\text { Number of } \\
\text { Fatalities }\end{array}$} \\
& \multicolumn{2}{c}{$(\log +1)$} \\
\hline 1-12 Weeks Post-Qualification & $-0.061^{*}$ & $-0.056^{* *}$ & $-0.149^{* *}$ & $-0.107^{* * *}$ & $-0.238^{* *}$ & $-0.169^{* *}$ \\
& $(0.032)$ & $(0.027)$ & $(0.069)$ & $(0.038)$ & $(0.100)$ & $(0.069)$ \\
$13-25$ Weeks Post-Qualification & $-0.090^{* *}$ & $-0.078^{* *}$ & $-0.214^{* *}$ & $-0.116^{* *}$ & $-0.229^{*}$ & $-0.144^{*}$ \\
& $(0.040)$ & $(0.035)$ & $(0.098)$ & $(0.054)$ & $(0.121)$ & $(0.080)$ \\
\hline Country $\times$ Qualifier FE & Yes & Yes & Yes & Yes & Yes & Yes \\
Week FE & Yes & Yes & Yes & Yes & Yes & Yes \\
4 Lags of Conflict & No & Yes & No & Yes & No & Yes \\
\hline Observations & 5,050 & 4,646 & 5,050 & 4,646 & 5,050 & 4,646 \\
R-squared & 0.010 & 0.024 & 0.014 & 0.119 & 0.012 & 0.070 \\
\hline \hline
\end{tabular}

$* * * \mathrm{p}<0.01, * * \mathrm{p}<0.05, * \mathrm{p}<0.1$ Robust standard errors in parentheses clustered at the country $\times$ qualifier level. Sample covers $+/-25$ weeks around the end of qualification process for 101 country $\times$ qualifier pairs. The variable 1-12 Weeks Post-Qualification takes value 1 during the 12 weeks immediately after the end of the qualification process for the countries that barely qualify to the ACN, 0 otherwise. The variable 13-25 Weeks Post-Qualification takes value 1 starting the 13th week after the end of the qualification process for the countries that barely qualify to the ACN, 0 otherwise. Conflict data comes from the ACLED dataset. 
To test this hypothesis in Table 10 we estimate our baseline specification separately for i) countries that had not qualified in three years or more (i.e., the sample mean) and ii) countries that had never qualified. The results provide strong support for the above-mentioned hypothesis: the reduction in the occurrence and intensity of conflict is generally larger and more significant for overdue and first qualifications, with the exception of the decrease in the number of fatalities which is marginally insignificant for first qualifications.

This pattern also sheds light on the natural experiment induced by WC qualification. ${ }^{31}$ Table A.15 in the Appendix shows that our results are essentially unaltered if we add instances of last-round qualification for the WC to our sample. The coefficients become slightly smaller in magnitude (though statistically indistinguishable), consistent with the fact that WC qualification generates a rather different kind of variation: there are relatively few Sub-Saharan countries qualifying, and many of them are traditional continental footballing powers such as Nigeria and Cameroon. In fact, Table A.16 shows that WC qualification also has a much stronger effect on conflict in first-time or "overdue" cases.

Finally, in Table A.17 we verify that the decline in conflict due to the national team qualifying to the ACN tournament applies to both urban and rural areas, with a slightly larger effect in cities for the occurrence and frequency of conflict events, and in rural areas for the number of associated fatalities (which is generally higher in these areas). ${ }^{32}$

\footnotetext{
${ }^{31}$ See Table A.14 for a list of countries involved in last-round qualification.

32 To code conflict events as either urban or rural we used polygons from urban areas of dense human habitation at $1 \mathrm{~km}$ resolution as defined in Kelso and Patterson (2012). Consequently, all conflict events in ACLED intersected with the urban polygons were coded as urban and the others as rural.
} 


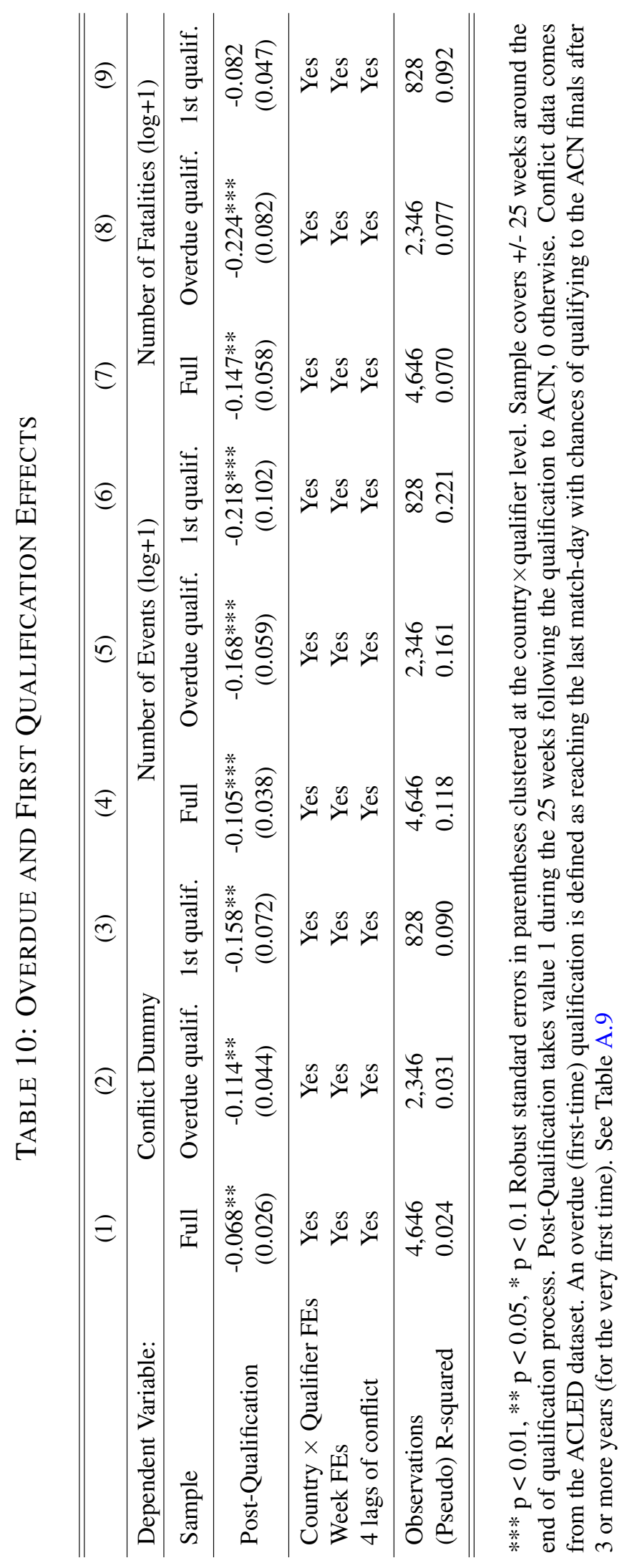


TABLE 11: IMPACT ON ETHNIC CONFLICT

\begin{tabular}{lccc}
\hline \hline & $(1)$ & $(2)$ & $(3)$ \\
\hline Dependent Variable: & $\begin{array}{c}\text { Dummy for } \\
\text { any Conflict }\end{array}$ & $\begin{array}{c}\text { Number of } \\
\text { Events (log+1) }\end{array}$ & $\begin{array}{c}\text { Number of } \\
\text { Fatalities (log+1) }\end{array}$ \\
\hline Post-Qualification & $-0.024^{* *}$ & $-0.022^{*}$ & $-0.066^{* *}$ \\
& $(0.012)$ & $(0.011)$ & $(0.031)$ \\
\hline Long-Run Impact & 0.029 & 0.034 & 0.086 \\
\hline Country $\times$ Qualifier FE & Yes & Yes & Yes \\
Week FE & Yes & Yes & Yes \\
4 Lags of Conflict & Yes & Yes & Yes \\
\hline Observations & 4,646 & 4,646 & 4,646 \\
R-squared & 0.029 & 0.083 & 0.055 \\
\hline \hline
\end{tabular}

*** $\mathrm{p}<0.01, * * \mathrm{p}<0.05, * \mathrm{p}<0.1$ Robust standard errors in parentheses clustered at the country $\times$ qualifier level. Sample covers $+/-25$ weeks around the end of qualification process. Post-Qualification takes value 1 during the 25 weeks following the qualification to ACN, and 0 otherwise. Ethic conflict is coded using conflict data from the ACLED dataset.

\subsection{QUALIFICATIONS AND ETHNIC CONFLICT}

In Table 11 we investigate the effect of qualification to the ACN tournament on conflict events classified as ethnically related according to the procedure described in section 2.3. When estimating our most comprehensive specification - with country $\times$ qualifier and week fixed effects and lags of conflict - we find that national team's qualification to the ACN finals reduced the occurrence of inter-ethnic violence (column 1), as well as its intensity measured both by the number of conflict events and associated fatalities (columns 2-3). Though smaller than for overall conflict, the effect is rather sizable, with the qualification reducing the likelihood of ethnic violence by one third of the mean value of the dummy variable. ${ }^{33}$

\subsection{ALTERNATIVE EXPLANATIONS}

Finally, we analyze two alternative explanations for the negative effect of qualification on conflict documented above. The first one is that the decline in conflict may be partly due to the coincidence with the ACN tournament, which, in some cases, took place within six months from qualification. Indeed, since the ACN finals are very popular and are broad-

${ }^{33}$ As shown in Table A.13, the results are similar when using the number of conflict events and fatalities instead of their $\log +1$ version. 
cast around the continent, they may distract many individuals who may otherwise engage in violence, particularly in countries that qualified. To test for this possibility, in Table 12 we re-estimate our baseline specification excluding from the sample the weeks during which ACN finals were taking place. The results indicate that, regardless of which measure of conflict we use and whether we control for lagged conflict, the effect of qualification on conflict remains virtually unchanged. ${ }^{34}$

\section{TABLE 12: EFFECT OF QUALIFICATION AND ACN FinAlS}

\begin{tabular}{lcccccc}
\hline \hline Dependent variable: & \multicolumn{2}{c}{$\begin{array}{c}\text { Dummy for } \\
\text { any conflict event }\end{array}$} & \multicolumn{2}{c}{$\begin{array}{c}\text { Number of } \\
\text { conflict events }(\log +1)\end{array}$} & \multicolumn{2}{c}{$\begin{array}{c}\text { Number of } \\
\text { fatalities }(\log +1)\end{array}$} \\
& $(1)$ & $(2)$ & $(3)$ & $(4)$ & $(5)$ & $(6)$ \\
\hline \multirow{2}{*}{ Post-Qualification } & $-0.076^{* *}$ & $-0.066^{* *}$ & $-0.179^{* *}$ & $-0.106^{* * *}$ & $-0.231^{* *}$ & $-0.151^{* *}$ \\
& $(0.031)$ & $(0.026)$ & $(0.070)$ & $(0.037)$ & $(0.094)$ & $(0.060)$ \\
\hline Country $\times$ Qualifier FE & Yes & Yes & Yes & Yes & Yes & Yes \\
Week FE & Yes & Yes & Yes & Yes & Yes & Yes \\
4 Lags of Conflict & No & Yes & No & Yes & No & Yes \\
Excluding ACN Finals & Yes & Yes & Yes & Yes & Yes & Yes \\
\hline Observations & 4,782 & 4,378 & 4,782 & 4,378 & 4,782 & 4,378 \\
R-squared & 0.010 & 0.023 & 0.015 & 0.112 & 0.013 & 0.071 \\
\hline \hline
\end{tabular}

$* * * \mathrm{p}<0.01, * * \mathrm{p}<0.05, * \mathrm{p}<0.1$ Robust standard errors in parentheses clustered at the country $\times$ qualifier level. Sample covers +/- 25 weeks around the end of qualification process, except for observations in weeks wherein the ACN finals took place, which are excluded (268 weekly observations). Conflict data comes from the ACLED dataset.

The second possibility relates to the news-based nature of the ACLED conflict data. A conflict event is recorded by ACLED only if it is mentioned by at least one of a multiplicity of local, national, or international media, (or if it is reported by local NGOs). It is in principle possible that the qualification of the national team to the ACN tournament may lead to an increase in the number of football-related news in local media that may crowd out news about the conflict, potentially leading to a mechanical reduction in the number of conflict events recorded by ACLED. ${ }^{35}$ To the extent that football-related news are likely more extensive

${ }^{34}$ As an additional test in appendix Table A.21 we look at the entire sample but include a dummy for the weeks during which the ACN's finals are taking place only for teams that qualified. The results are largely consistent with those in Table 12.

${ }^{35}$ Evidence that news coverage of important sporting events on TV can crowd out news about other issues, such as natural disasters or conflict, is available from Eisensee and Stromberg (2007) and Durante and Zhuravskaya (forthcoming). 
during the finals of the ACN, the results in Table A.21 are reassuring that this aspect is not driving our results. Yet, it could be that football-news increase in the months prior to the ACN finals, as the discussion about players' selection and teams' prospects intensifies. One way to test for the crowding-out hypothesis is to verify that the effect is not driven by less severe conflict events which should be more likely to go unreported due to competition from football news than events involving a higher number of fatalities. We implement this approach in Table 13 where we estimate our baseline specification for the occurrence of conflict events of increasing severity, i.e. involving 10 or more fatalities, 25 or more fatalities, and 50 or more fatalities. The fact that the results are similar for the different samples, both in terms of magnitude and significance, suggest that reporting bias is not driving our results.

TABle 13: CONFlict OCCURRENCE B y NuMber of FATALities

\begin{tabular}{lcccccc}
\hline \hline Dependent Variable: & \multicolumn{5}{c}{ Dummy for at least one conflict event in a week } \\
\hline & \multicolumn{2}{c}{ Events with } & \multicolumn{2}{c}{ Events with } & \multicolumn{2}{c}{ Events with } \\
& $\begin{array}{c}\text { 10 or more fatalities } \\
(1)\end{array}$ & $(2)$ & $(3)$ & $(4)$ & $\begin{array}{c}\text { 25 or more fatalities } \\
50 \text { or more fatalities }\end{array}$ \\
& $-0.042^{* *}$ & $-0.035^{* *}$ & $-0.034^{* *}$ & $-0.027^{*}$ & $-0.030^{* *}$ & $-0.022^{*}$ \\
Post-Qualification & $(0.021)$ & $(0.016)$ & $(0.016)$ & $(0.014)$ & $(0.013)$ & $(0.012)$ \\
\hline Mean dep. variable & 0.089 & 0.089 & 0.043 & 0.042 & 0.024 & 0.023 \\
\hline Country $\times$ Qualifier FE & Yes & Yes & Yes & Yes & Yes & Yes \\
Week FE & Yes & Yes & Yes & Yes & Yes & Yes \\
4 Lags of Conflict & No & Yes & No & Yes & No & Yes \\
\hline Observations & 5,050 & 4,646 & 5,050 & 4,646 & 5,050 & 4,646 \\
R-squared & 0.010 & 0.026 & 0.011 & 0.045 & 0.012 & 0.053 \\
\hline \hline
\end{tabular}

$* * * \mathrm{p}<0.01, * * \mathrm{p}<0.05, * \mathrm{p}<0.1$ Robust standard errors in parentheses clustered at the country $\times$ qualifier level. Sample covers $+/-25$ weeks around the end of qualification process. Conflict data comes from the ACLED dataset.

\section{CONCLUSIONS}

We have shown that collectively shared experiences of the type induced by sports - and international football in particular - can shape identities in ways that can help build national sentiment at the expense of ethnic identification. In the context of Sub-Saharan Africa, we find that individuals interviewed in the days immediately after a victory of their national football team are less likely to report a strong sense of ethnic (as opposed to national) iden- 
tity than those interviewed just before. The estimated effect is sizable - accounting for a $20 \%$ decrease in the average probability of ethnic self-identification - and robust to different specifications and controls.

Exposure to national teams' victories is also associated with a higher level of trust in others, in general, and in individuals of other ethnicities, in particular. These effects appear to be driven by a genuine increase in national pride rather than generic post-victory euphoria; indeed national team's victories have no significant impact on other attitudes such as support for the government or optimism about present and future economic conditions.

Importantly, we show that the impact translates into tangible outcome, by looking at the evolution of civil conflict around the time of important national teams' achievements. Specifically, we find that countries whose national teams (barely) qualified to the finals of the Africa Cup of Nations, experience significantly less conflict in the six months after the qualification than countries whose teams (barely) did not qualify. This effect is not only sizable and statistically significant, but also persists for several months after the successful event.

Our findings suggest a number of policy-relevant implications that go well beyond the realm of sports. First, policies that favor emotional participation - which could be triggered, say, by religious or civic events - may be most effective at forging a shared sentiment of unity and set the foundations for more long-lasting cultural and political changes. They also highlight that nation-building strategies are available even in contexts of low state capacity, and might work as a substitute for other more demanding nation-building tools, especially by illustrating how different groups can successfully cooperate.

Needless to say, the power of these shared collective experiences need not be used for good. Even in our specific context, it is certainly possible that the reduction in friction and violence within countries could coexist with increased conflictuality with other countries, especially to the extent that the strengthening of national identity is taking place in a context of contrast with foreign adversaries. More broadly, the passions arisen by sports can certainly be channeled to violence in other contexts as well. These remain interesting topics for future research. 


\section{REFERENCES}

Adida, Claire L., Karen E. Ferree, Daniel N. Posner, and Amanda Lea Robinson, "Who's Asking? Interviewer Coethnicity Effects in African Survey Data," Comparative Political Studies, 2016, 49 (12), 1630-1660.

Afrobarometer, Round 4 Survey Manual, Afrobarometer, 2007.

Alesina, Alberto and Bryony Reich, "Nation Building," Working Paper 18839, National Bureau of Economic Research February 2015.

_ and Eliana La Ferrara, "Preferences for redistribution in the land of opportunities," Journal of Public Economics, 2005, 89 (5), 897-931.

_ , Bryony Reich, and Alessandro Riboni, "Nation-Building, Nationalism and Wars," Working Paper 23435, National Bureau of Economic Research 2017.

_ , Reza Baqir, and William Easterly, "Public Goods and Ethnic Divisions*," The Quarterly Journal of Economics, 1999, 114 (4), 1243-1284.

Allison, L, "Sport and Nationalism," in J Coakley an E. Dunning, ed., Handbook of Sports Studies, London: SAGE Publications Ltd, 2000, chapter 22, pp. 345-356.

Alvarez, Javier and Manuel Arellano, "The Time Series and Cross-Section Asymptotics of Dynamic Panel Data Estimators," Econometrica, 2003, 71 (4), 1121-1159.

Anderson, Benedict, Imagined Communities: Reflections on the Origin and Spread of Nationalism, Verso, 1983.

Anderson, Michael L., "Multiple Inference and Gender Differences in the Effects of Early Intervention: A Reevaluation of the Abecedarian, Perry Preschool, and Early Training Projects," Journal of the American Statistical Association, 2008, 103 (484), 1481-1495.

Armstrong, Gary, "Talking up the game: Football and the reconstruction of Liberia, West Africa," Identities: Global Studies in Culture and Power, 2002, 9 (4), 471-494.

Bandiera, Oriana, Myra Mohnen, Imran Rasul, and Martina Viarengo, "Nation-Building through Compulsory Schooling during the Age of Mass Migration,” The Economic Journal, 2018.

Bandyopadhyay, Sanghamitra and Elliott Green, "Nation-building and conflict in modern Africa," World Development, 2013, 45, 108-118.

Bazzi, Samuel, Arya Gaduh, Alexander Rothenberg, and Maisy Wong, "Unity in Diversity? How Intergroup Contact Can Foster Nation Building,” Working Paper, 2018.

Bel, Germà, "Infrastructure and nation building: The regulation and financing of network transportation infrastructures in Spain (1720-2010)," Business History, 2011, 53 (5), 688-705.

Billig, Michael, "Banal Nationalism,” 1995.

Buggle, Johannes C, "Law and social capital: Evidence from the Code Napoleon in Germany," European Economic Review, 2016, 87, 148-175. 
Card, David and Gordon B Dahl, "Family violence and football: The effect of unexpected emotional cues on violent behavior," The Quarterly Journal of Economics, 2011, pp. 103-143.

Carlin, John, Playing the Enemy: Nelson Mandela and the Game that Made a Nation, Penguin Books, 2008.

Cederman, Lars-Erik, Kristian Skrede Gleditsch, Idean Salehyan, and Julian Wucherpfennig, “Transborder ethnic kin and civil war," International Organization, 2013, 67 (02), 389-410.

Cialdini, Robert B and Kenneth D Richardson, "Two indirect tactics of image management: Basking and blasting.," Journal of personality and social psychology, 1980, 39 (3), 406.

- and Maralou E De Nicholas, "Self-presentation by association.," Journal of personality and social psychology, 1989, 57 (4), 626.

_, Richard J Borden, Avril Thorne, Marcus Randall Walker, Stephen Freeman, and Lloyd Reynolds Sloan, "Basking in reflected glory: Three (football) field studies.," Journal of personality and social psychology, 1976, 34 (3), 366.

Conversi, Daniele, “'We are all equals!' Militarism, homogenization and 'egalitarianism' in nationalist state-building (1789-1945)," Ethnic and racial studies, 2008, 31 (7), 1286-1314.

Darby, Paul, Africa, football, and FIFA: Politics, colonialism, and resistance, Vol. 23, Psychology Press, 2002.

_ , "'Let Us Rally Around the Flag': Football, National-Building, and Pan-Africanism in Kwame Nkrumah's Ghana," The Journal of African History, 2013, 54 (02), 221-246.

_- "Moving players, traversing perspectives: Global value chains, production networks and Ghanaian football labour migration," Geoforum, 2013, 50, 43-53.

Durante, Ruben, "Risk, Cooperation and the Economic Origins of Social Trust: an Empirical Investigation," 2011.

_ and Ekaterian Zhuravskaya, "Attack when the World is not Watching? U.S. Media and the Israeli-Palestinian Conflict," Journal of Political Economy, forthcoming.

Easterly, William and Ross Levine, "Africa's growth tragedy: policies and ethnic divisions," The Quarterly Journal of Economics, 1997, pp. 1203-1250.

Eifert, Benn, Edward Miguel, and Daniel N Posner, "Political competition and ethnic identification in Africa," American Journal of Political Science, 2010, 54 (2), 494-510.

Eisensee, Thomas and David Stromberg, "News droughts, news floods, and US disaster relief," The Quarterly Journal of Economics, 2007, 122, 693-728.

Fearon, James D. and David D. Laitin, "Ethnicity, Insurgency, and Civil War," American Political Science Review, 2003, 97, 75-90.

Finer, Samuel E, "State-and nation-building in Europe: the role of the military," in Charles Tilly, ed., The formation of national states in Western Europe, Princeton University Press Princeton, 1975, pp. 84-163. 
Francois, Patrick, Ilia Rainer, and Francesco Trebbi, "How is power shared in Africa?," Econometrica, 2015, 83 (2), 465-503.

Green, Elliot D., "Ethnicity, national identity and the state: evidence from sub-Saharan Africa.," British Journal of Political Science, 2017.

Hargreaves, John, "Olympism and Nationalism: Some Preliminary Consideration," International Review for the Sociology of Sport, 1992, 27 (2), 119-135.

Healy, Andrew J, Neil Malhotra, and Cecilia Hyunjung Mo, "Irrelevant events affect voters' evaluations of government performance," Proceedings of the National Academy of Sciences, 2010, 107 (29), 12804-12809.

Heinila, Kalevi, "Sport and International UnderstandingâĂŤA Contradiction in Terms?," Sociology of Sport Journal, 1985, 2 (3), 240-248.

Herbst, Jeffrey, States and power in Africa: Comparative lessons in authority and control, Princeton University Press, 2014.

Hilton, Christopher, How Hitler Hijacked World Sport: The World Cup, the Olympics, the Heavyweight Championship and the Grand Prix, The History Press, 2011.

Hobsbawm, E. J., Nations and nationalism since 1870: Programme, myth, reality, Cambridge University Press, 1990.

Horner, Elka Peterson, "Rally Around the Flag and Support the Black Stars: Multi-Relational Analysis of Nationalism and Contemporary Football in Ghana," 2010.

Jacob, Marcus and Marcel Tyrell, "The Legacy of Surveillance: an Explanation for Social Capital Erosion and the Persistent Economic Disparity between East and West Germany," Available at SSRN 1554604, 2010.

Judson, Ruth A and Ann L Owen, "Estimating dynamic panel data models: a guide for macroeconomists," Economics letters, 1999, 65 (1), 9-15.

Kaplan, Ethan and Sharun Mukand, “The Persistence of Political Partisanship: Evidence from 9/11,” Working Paper, IIES 2014.

Kelso, N.V. and T. Patterson, "World Urban Areas, LandScan, 1:10 million," Technical Report, Made with Natural Earth 2012.

Kurzban, Robert, John Tooby, and Leda Cosmides, "Can race be erased? Coalitional computation and social categorization," Proceedings of the National Academy of Sciences, 2001, 98 (26), 15387-15392.

Lowe, Matt, “Types of Contact: A Field Experiment on Collaborative and Adversarial Caste Integration," Unpublished Manuscript, 2018.

Madestam, Andreas and David Yanagizawa-Drott, "Shaping the Nation: The Effect of Fourth of July on Political Preferences and Behavior in the United States," Working Paper 12034, Harvard Kennedy School 2012. 
Mamdani, Mahmood, When victims become killers: Colonialism, nativism, and the genocide in Rwanda, Princeton University Press, 2014.

Mehler, Andreas, "Political discourse in football coverage-the cases of Cote d'Ivoire and Ghana," Soccer \& Society, 2008, 9 (1), 96-110.

Michalopoulos, Stilyanos and Elias Papaioannou, "The Long-Run Effects of the Scramble for Africa," American Economic Review, forthcoming.

Miguel, Edward, "Tribe or nation? Nation building and public goods in Kenya versus Tanzania," World Politics, 2004, 56 (03), 328-362.

_ and Mary Kay Gugerty, "Ethnic diversity, social sanctions, and public goods in Kenya," Journal of Public Economics, 2005, 89 (11), 2325-2368.

Munyo, Ignacio and Martín A Rossi, "Frustration, euphoria, and violent crime," Journal of Economic Behavior \& Organization, 2013, 89, 136-142.

Nickell, Stephen, "Biases in dynamic models with fixed effects," Econometrica: Journal of the Econometric Society, 1981, pp. 1417-1426.

Nunn, Nathan and Leonard Wantchekon, "The Slave Trade and the Origins of Mistrust in Africa," American Economic Review, 2011, 101 (7), 3212-3252.

Platow, Michael, Maria Durante, Naeidra Williams, Matthew Garrett, Jarrod Walshe, Steven Cincotta, George Lianos, and Ayla Barutchu, "The Contribution of Sport Fan Social Identity to the Production of Prosocial Behavior," Group Dynamics: Theory, Research, and Practice, 06 1999, 3, 161-169.

Ramirez, Francisco $\mathbf{O}$ and John Boli, "The political construction of mass schooling: European origins and worldwide institutionalization," Sociology of education, 1987, pp. 2-17.

Robinson, Amanda Lea, "National versus ethnic identification in Africa: Modernization, colonial legacy, and the origins of territorial nationalism," World Politics, 2014, 66 (04), 709-746.

_ , "Nationalism and Inter-Ethnic Trust: Experimental Evidence from an African Border Region," Comparative Political Studies, forthcoming.

Salehyan, Idean, Cullen S Hendrix, Jesse Hamner, Christina Case, Christopher Linebarger, Emily Stull, and Jennifer Williams, "Social conflict in Africa: A new database," International Interactions, 2012, 38 (4), 503-511.

Stormer, Neil, "More than a game," Common Ground News Service, 2006, 20 June 2006.

Tilly, Charles, "Reflections on the History of European State-Making," in Charles Tilly, ed., The formation of national states in Western Europe, Princeton University Press Princeton, 1975, pp. 3 83 .

Vidacs, Bea, "Through the prism of sports: why should Africanists study sports?," Africa Spectrum, 2006, pp. 331-349.

_ , "Banal nationalism, football, and discourse community in Africa," Studies in Ethnicity and Nationalism, 2011, 11 (1), 25-41. 
Vigdor, Jacob L, “Interpreting ethnic fragmentation effects," Economics Letters, 2002, 75 (2), 271276.

Weber, Eugen, Peasants into Frenchmen: The Modernization of Rural France, 1870-1914, Stanford University Press, 1976.

West, Brady T. and Annelies G. Blom, "Explaining Interviewer Effects: A Research Synthesis," Journal of Survey Statistics and Methodology, 2017, 5 (2), 175-211.

Yanagizawa-Drott, David, "Propaganda and conflict: Evidence from the Rwandan genocide," The Quarterly Journal of Economics, 2014, 129 (4), 1947-1994. 
OnLINE APPENDiX - Not FOR PUbliCATION

AdDitional Figures And TABLES

Figure A.1: Ethnic Identity Before And After National Team's Victories INCLUDING COUNTRY-MATCH FIXED EFFECT

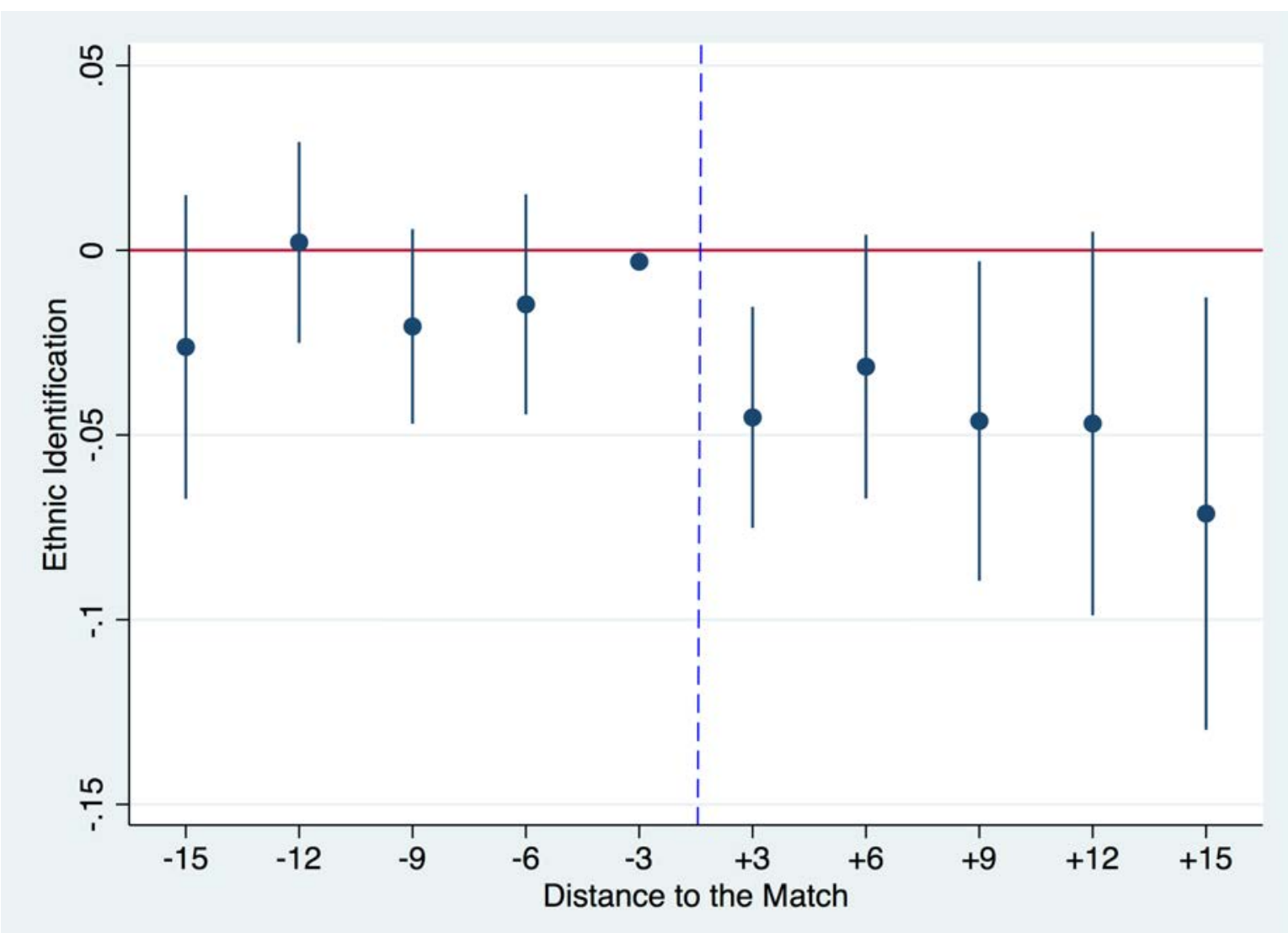

The figure plots the coefficients and the $95 \%$ confidence intervals for nine dummies indicating 3-day blocks from 15 days before to 15 days after a victory of the national football team. The coefficient for the period between 3 to 1 days before the match is normalized to zero. Confidence intervals are based on heteroskedasticity-robust standard errors clustered by language group $\times$ year. The coefficients are estimated from a unique regression in which we control for individual characteristics, country $\times$ match and language group $\times$ year fixed effects, and for the proximity to draws or defeats. 
TABle A.1: Summary STATISTICS

\begin{tabular}{lccccc}
\hline \hline \multicolumn{1}{c}{ Variable } & Mean & Std. Dev. & Min. & Max. & N \\
\hline Ethnic over National Identity & 0.149 & 0.356 & 0 & 1 & 28758 \\
Post-Play & 0.505 & 0.5 & 0 & 1 & 28758 \\
Post-Victory & 0.181 & 0.385 & 0 & 1 & 28758 \\
Post-Defeat & 0.225 & 0.418 & 0 & 1 & 28758 \\
Post-Draw & 0.099 & 0.299 & 0 & 1 & 28758 \\
Generalized Trust & 1.946 & 0.826 & 0 & 3 & 25475 \\
Inter-Ethnic Trust & 1.414 & 1.057 & 0 & 3 & 7992 \\
Intra-Ethnic Trust & 1.734 & 1.054 & 0 & 3 & 8078 \\
Trust in Ruling Party & 1.544 & 1.128 & 0 & 3 & 27270 \\
President's Approval & 2.759 & 0.963 & 1 & 4 & 27330 \\
Country's Economic Conditions Today (1=Good) & 0.268 & 0.443 & 0 & 1 & 28752 \\
Country's Economic Conditions Future (1=Good) & 0.526 & 0.499 & 0 & 1 & 28746 \\
Own Economic Conditions Today (1=Good) & 0.291 & 0.454 & 0 & 1 & 28725 \\
Own Economic Conditions Future (1=Good) & 0.561 & 0.496 & 0 & 1 & 28733 \\
Male & 0.505 & 0.5 & 0 & 1 & 28758 \\
Age & 36.4 & 14.537 & 18 & 130 & 28758 \\
Unemployed & 0.294 & 0.456 & 0 & 1 & 28758 \\
Rural Status & 0.628 & 0.483 & 0 & 1 & 28758 \\
Education & 3.023 & 2.078 & 0 & 9 & 28758 \\
Major Ethnicity & 0.383 & 0.486 & 0 & 1 & 28758 \\
Public Goods Provided & 0.47 & 0.305 & 0 & 1 & 28758 \\
\hline \hline
\end{tabular}


TABle A.2: LAnguage Group vs Ethnicity FE

\begin{tabular}{lccc}
\hline \hline \multicolumn{2}{c}{ Dependent Variable: } & \multicolumn{3}{c}{ Ethnic over } & National Identity & $(0-1$ dummy) \\
& $(1)$ & $(2)$ & $(3)$ \\
\hline Post-Victory & $-0.038^{* *}$ & $-0.039^{* *}$ & $-0.036^{* * *}$ \\
& $(0.015)$ & $(0.015)$ & $(0.014)$ \\
\hline Individual Controls & Yes & Yes & Yes \\
Country-Match FE & Yes & Yes & Yes \\
Identity $\times$ Year FE & Yes & Yes & Yes \\
Identity & Language & Language & Ethnicity \\
\hline Sample & Main & Overlapping & Overlapping \\
Observations & 28,758 & 24,809 & 24,809 \\
R-squared & 0.117 & 0.112 & 0.115 \\
\hline
\end{tabular}

$* * * \mathrm{p}<0.01, * * \mathrm{p}<0.05, * \mathrm{p}<0.1$ Robust standard errors clustered at the identity group $\times$ year level in parentheses. Victory takes value 1 if the respondent was interviewed within 15 days after a victory, 0 otherwise. 
TABle A.3: ORdered Dependent VARIABle

\begin{tabular}{lcccc}
\hline \hline & \multicolumn{2}{c}{ Dependent Variable: Ethnic Identity (Ordered, 0-4) } \\
& \multicolumn{2}{c}{ OLS } & \multicolumn{2}{c}{ Ordered Probit } \\
\cline { 2 - 5 } & $(1)$ & $(2)$ & $(3)$ & $(4)$ \\
\hline Post-Victory & $-0.081^{* *}$ & -0.050 & $-0.088^{* *}$ & -0.057 \\
& $(0.038)$ & $(0.041)$ & $(0.038)$ & $(0.040)$ \\
\hline Country $\times$ Year FE & Yes & No & Yes & No \\
Individual Controls & Yes & Yes & Yes & Yes \\
Language $\times$ Year FE & Yes & Yes & Yes & Yes \\
Country-Match FE & No & Yes & No & Yes \\
\hline Observations & 25,293 & 25,293 & 25,293 & 25,293 \\
\hline \hline
\end{tabular}

$* * * \mathrm{p}<0.01, * * \mathrm{p}<0.05, * \mathrm{p}<0.1$ Robust standard errors clustered at the language group $\times$ year level in parentheses. Victory takes value 1 if the respondent was interviewed within 15 days after a victory, 0 otherwise. 
Table A.4: Alternative Time-Windows

\begin{tabular}{lcccccc}
\hline \hline & \multicolumn{5}{c}{ Dependent Variable: Ethnic over National Identity (0-1 dummy) } \\
\cline { 2 - 7 } & $(1)$ & $(2)$ & $(3)$ & $(4)$ & $(5)$ & $(6)$ \\
& $+/-15$ Days & $+/-5$ days & $+/-10$ days & $+/-20$ days & $+/-25$ days & $+/-30$ days \\
\hline \multirow{2}{*}{ Post-Victory } & $-0.037^{* *}$ & $-0.040^{* * *}$ & $-0.035^{* *}$ & $-0.037^{* *}$ & $-0.036^{* *}$ & $-0.037^{* *}$ \\
& $(0.015)$ & $(0.015)$ & $(0.015)$ & $(0.015)$ & $(0.015)$ & $(0.015)$ \\
& {$[0.02]$} & {$[0.01]$} & {$[0.03]$} & {$[0.03]$} & {$[0.03]$} & {$[0.03]$} \\
\hline Country $\times$ Match FE & Yes & Yes & Yes & Yes & Yes & Yes \\
Individual Controls & Yes & Yes & Yes & Yes & Yes & Yes \\
Language $\times$ Year FE & Yes & Yes & Yes & Yes & Yes & Yes \\
\hline Observations & 28,758 & 10,901 & 19,438 & 32,785 & 38,459 & 43,600 \\
R-squared & 0.110 & 0.153 & 0.130 & 0.110 & 0.108 & 0.110 \\
\hline \hline
\end{tabular}

$* * * \mathrm{p}<0.01, * * \mathrm{p}<0.05, * \mathrm{p}<0.1$ Robust standard errors clustered by language group $\times$ year in parentheses. False Discovery Rate (FDR) adjusted p-values are reported in square brackets (Anderson, 2008). PostVictory takes value 1 if the respondent was interviewed in the $x$ days following a victory of the national team, with the value of $x$ indicated at the top of each column, and 0 otherwise. 
TABle A.5: Multiple GAmes

\begin{tabular}{|c|c|c|c|c|c|c|}
\hline \multirow[b]{3}{*}{ Share of Victories } & \multicolumn{6}{|c|}{ Panel A: Share of Victories } \\
\hline & $\begin{array}{c}\text { Ethnic } \\
\text { Identification } \\
(1) \\
\end{array}$ & $\begin{array}{c}\text { Generalized } \\
\text { Trust } \\
\text { (2) }\end{array}$ & $\begin{array}{c}\text { Inter-Ethnic } \\
\text { Trust } \\
\text { (3) }\end{array}$ & $\begin{array}{c}\text { Inter-Ethnic } \\
\text { Trust Premium } \\
\text { (4) }\end{array}$ & $\begin{array}{c}\text { Trust in } \\
\text { Ruling Party } \\
\text { (5) }\end{array}$ & $\begin{array}{c}\text { President's } \\
\text { Approval } \\
(6)\end{array}$ \\
\hline & $\begin{array}{c}-0.040 * * * \\
(0.013)\end{array}$ & $\begin{array}{c}0.055 \\
(0.042)\end{array}$ & $\begin{array}{r}0.234 * * \\
(0.102)\end{array}$ & $\begin{array}{l}0.056^{*} \\
(0.028)\end{array}$ & $\begin{array}{c}0.008 \\
(0.032)\end{array}$ & $\begin{array}{c}0.044 \\
(0.033)\end{array}$ \\
\hline \multirow[t]{2}{*}{ R-squared } & $\begin{array}{c}35,069 \\
0.110 \\
\end{array}$ & $\begin{array}{c}33,910 \\
0.239 \\
\end{array}$ & $\begin{array}{l}8,202 \\
0.190 \\
\end{array}$ & $\begin{array}{l}8,188 \\
0.056 \\
\end{array}$ & $\begin{array}{c}37,735 \\
0.174 \\
\end{array}$ & $\begin{array}{c}37,556 \\
0.231 \\
\end{array}$ \\
\hline & $\begin{array}{c}\text { Ethnic } \\
\text { Identification } \\
\text { (1) }\end{array}$ & $\begin{array}{c}\text { Generalized } \\
\text { Trust } \\
\text { (2) }\end{array}$ & $\begin{array}{c}\text { Panel B: Shar } \\
\text { Inter-Ethnic } \\
\text { Trust } \\
\text { (3) }\end{array}$ & $\begin{array}{l}\text { of Points Won } \\
\text { Inter-Ethnic } \\
\text { Trust Premium } \\
\text { (4) }\end{array}$ & $\begin{array}{c}\text { Trust in } \\
\text { Ruling Party } \\
\text { (5) }\end{array}$ & $\begin{array}{c}\text { President's } \\
\text { Approval } \\
\text { (6) }\end{array}$ \\
\hline Share of Points Won & $\begin{array}{c}-0.040 * * * \\
(0.013) \\
\end{array}$ & $\begin{array}{l}0.063^{*} \\
(0.036) \\
\end{array}$ & $\begin{array}{c}0.234 * * \\
(0.102) \\
\end{array}$ & $\begin{array}{l}0.056^{*} \\
(0.028) \\
\end{array}$ & $\begin{array}{c}0.006 \\
(0.032) \\
\end{array}$ & $\begin{array}{c}0.045 \\
(0.033) \\
\end{array}$ \\
\hline $\begin{array}{l}\text { Observations } \\
\text { R-squared }\end{array}$ & $\begin{array}{c}35,069 \\
0.110 \\
\end{array}$ & $\begin{array}{c}33,910 \\
0.240 \\
\end{array}$ & $\begin{array}{l}8,202 \\
0.190 \\
\end{array}$ & $\begin{array}{l}8,188 \\
0.056 \\
\end{array}$ & $\begin{array}{c}37,735 \\
0.167 \\
\end{array}$ & $\begin{array}{c}37,556 \\
0.231 \\
\end{array}$ \\
\hline $\begin{array}{l}\text { Multiple Games } \\
\text { Country } \times \text { Year FE } \\
\text { Individual Controls } \\
\text { Language } \times \text { Year FE }\end{array}$ & $\begin{array}{l}\text { Yes } \\
\text { Yes } \\
\text { Yes } \\
\text { Yes }\end{array}$ & $\begin{array}{l}\text { Yes } \\
\text { Yes } \\
\text { Yes } \\
\text { Yes }\end{array}$ & $\begin{array}{l}\text { Yes } \\
\text { Yes } \\
\text { Yes } \\
\text { Yes }\end{array}$ & $\begin{array}{l}\text { Yes } \\
\text { Yes } \\
\text { Yes } \\
\text { Yes }\end{array}$ & $\begin{array}{l}\text { Yes } \\
\text { Yes } \\
\text { Yes } \\
\text { Yes }\end{array}$ & $\begin{array}{l}\text { Yes } \\
\text { Yes } \\
\text { Yes } \\
\text { Yes }\end{array}$ \\
\hline
\end{tabular}

$* * * \mathrm{p}<0.01, * * \mathrm{p}<0.05, * \mathrm{p}<0.1$ Robust standard errors clustered at the language group $\times$ year level in parentheses. Share of Victories accounts for the fraction of total games won. Share of points Won accounts for the fraction of total possible points obtained (a win, draw, and lose awards 3,1 , and 0 points, respectively). 
TAble A.6: Victories And Ethnic Identification: Heterogenous EfFeCts

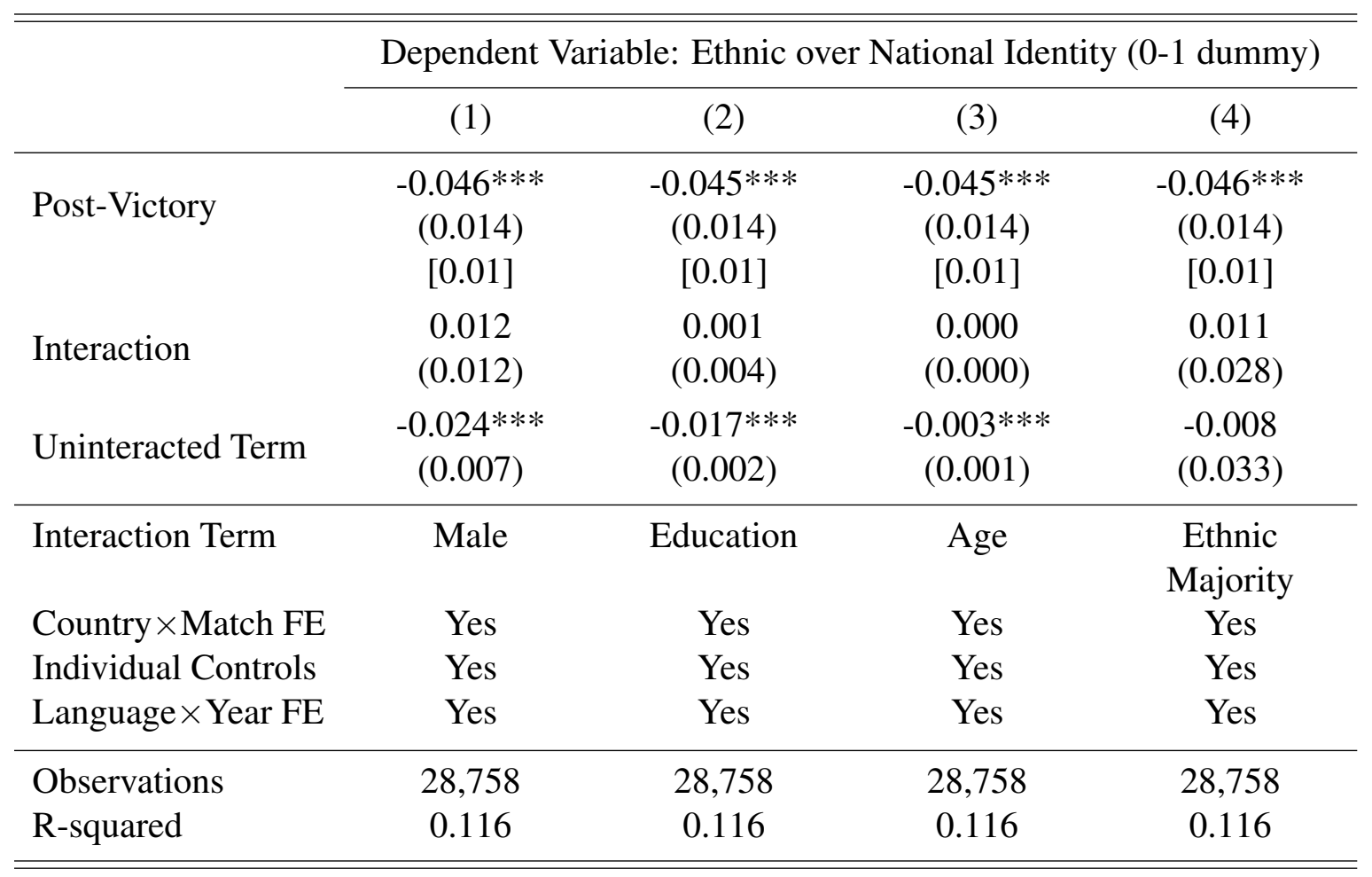

$* * * \mathrm{p}<0.01, * * \mathrm{p}<0.05, * \mathrm{p}<0.1$ Robust standard errors clustered at the language group $r \times$ year level in parentheses. False Discovery Rate (FDR) adjusted p-values are reported in square brackets (Anderson, 2008). Post-Victory takes value 1 if the respondent was interviewed in the 15 days after a victory, 0 otherwise. To ease the comparison with previous tables, variables in the interaction terms were demeaned. 
TABle A.7: TEAM Diversity

\begin{tabular}{lcc} 
Country & Year & Team Diversity \\
\hline \hline BOTSWANA & 2003 & 0.885 \\
BOTSWANA & 2008 & 0.854 \\
CAMEROON & 2013 & 0.817 \\
GHANA & 2002 & 0.617 \\
GHANA & 2005 & 0.634 \\
GHANA & 2012 & 0.640 \\
KENYA & 2005 & 0.760 \\
KENYA & 2011 & 0.654 \\
NIGERIA & 2005 & 0.816 \\
NIGERIA & 2013 & 0.761 \\
SENEGAL & 2005 & 0.832 \\
SENEGAL & 2008 & 0.834 \\
SIERRA LEONE & 2012 & 0.727 \\
TANZANIA & 2003 & 0.920 \\
TANZANIA & 2008 & 0.866 \\
TANZANIA & 2012 & 0.898 \\
UGANDA & 2002 & 0.334 \\
UGANDA & 2008 & 0.450 \\
UGANDA & 2012 & 0.112 \\
ZAMBIA & 2003 & 0.621 \\
ZAMBIA & 2009 & 0.758 \\
ZAMBIA & 2012 & 0.687 \\
ZAMBIA & 2013 & 0.740 \\
ZIMBABWE & 2005 & 0.840 \\
\hline \hline
\end{tabular}

Team diversity is computed as the ethnolinguistic fractionalization index based in the ethnic composition of the national team in the same year of the Afrobarometer's wave used in the main analysis. 
Table A.8: Summary Statistics Conflict Measures

\begin{tabular}{lcccc}
\hline \hline \multicolumn{1}{c}{ Variable } & Mean & Std. Dev. & Min. & Max. \\
\hline Conflict Dummy & 0.406 & 0.491 & 0 & 1 \\
Number of Events $(\log +1)$ & 0.618 & 0.907 & 0 & 4.263 \\
Number of Fatalities $(\log +1)$ & 0.544 & 1.251 & 0 & 10.131 \\
Ethnic Conflict Dummy & 0.062 & 0.242 & 0 & 1 \\
Number of Ethnic Events $(\log +1)$ & 0.065 & 0.277 & 0 & 2.773 \\
Number of Ethnic Fatalities $(\log +1)$ & 0.115 & 0.604 & 0 & 6.909 \\
Riot Dummy & 0.188 & 0.39 & 0 & 1 \\
Attack on Civilians Dummy & 0.234 & 0.423 & 0 & 1 \\
Government Event Dummy & 0.268 & 0.443 & 0 & 1 \\
Battle Event Dummy & 0.188 & 0.391 & 0 & 1 \\
Number of Riot Events (log + 1) & 0.194 & 0.458 & 0 & 3.807 \\
Number of Attack on Civ. $(\log +1)$ & 0.286 & 0.598 & 0 & 3.892 \\
Number of Gov. Events $(\log +1)$ & 0.346 & 0.666 & 0 & 3.871 \\
Number of Battles (log + 1) & 0.252 & 0.59 & 0 & 3.466 \\
Number of Fatalities in Riots $(\log +1)$ & 0.029 & 0.23 & 0 & 4.836 \\
Number of Fatalities due to Attack on Civ. $(\log +1)$ & 0.294 & 0.874 & 0 & 10.127 \\
Number of Fatalities in Government Events $(\log +1)$ & 0.308 & 0.93 & 0 & 6.987 \\
Number of Fatalities in Battles (log +1) & 0.334 & 1.002 & 0 & 6.987 \\
\hline Sample Size & 5,050 weeks & & \\
\hline
\end{tabular}


TAble A.9: Treatment and CONTRol Groups By Qualifying Process

\begin{tabular}{|c|c|c|}
\hline Tournament Year & Treatment Group & Control Group \\
\hline 1998 & $\begin{array}{l}\text { Angola, Namibia, } D R C \text {, and } \\
\text { Mozambique }\end{array}$ & $\begin{array}{l}\text { Zimbabwe, Mali, Senegal, Gabon, } \\
\text { Liberia, and Malawi }\end{array}$ \\
\hline 2000 & Togo, Ivory Coast, and Congo & Guinea, Mali, Liberia, and Uganda \\
\hline 2002 & Zambia, Burkina Faso, and DRC & $\begin{array}{l}\text { Angola, Zimbabwe, Madagascar } \\
\text { Lesotho, and Gabon }\end{array}$ \\
\hline 2004 & $\begin{array}{l}\text { Benin, Kenya, Rwanda, Mali, DRC, } \\
\text { South Africa, and Zimbabwe }\end{array}$ & $\begin{array}{l}\text { Zambia, Togo, Sierra Leone, Ivory } \\
\text { Coast, Madagascar, and Uganda }\end{array}$ \\
\hline 2006 & DRC and South Africa & Burkina Faso \\
\hline 2008 & $\begin{array}{l}\text { Ivory Coast, Sudan, Senegal, } \\
\text { Guinea, Namibia, Benin, and } \\
\text { South Africa }\end{array}$ & $\begin{array}{l}\text { Gabon, Gambia, Uganda, Eritrea } \\
\text { Equatorial Guinea, Mozambique, } \\
\text { and DRC }\end{array}$ \\
\hline 2010 & Zambia and Malawi & Rwand $a$ and Guinea \\
\hline 2012 & $\begin{array}{l}\text { Mali, Guinea, Niger, Angola, } \\
\text { and Sudan }\end{array}$ & $\begin{array}{l}\text { Zimbabwe, Sierra Leone, Nigeria, } \\
\text { Malawi, South Africa, Cameroon, } \\
\text { Cape Verde, Uganda, Kenya, CAR, } \\
\text { and Gambia }\end{array}$ \\
\hline 2013 & $\begin{array}{l}\text { Ivory Coast,Ethiopia, Cape } \\
\text { Verde, Niger, Angola, Togo, } \\
\text { DRC, Burkina Faso, Ghana, } \\
\text { Mali, Nigeria, and Zambia }\end{array}$ & $\begin{array}{l}\text { Malawi, Botswana, Uganda, Sierra } \\
\text { Leone, Senegal, Liberia, Cameroon, } \\
\text { Equatorial Guinea, Sudan, Guinea, } \\
\text { Mozambique, Zimbabwe, Gabon, } \\
\text { and } \boldsymbol{C A R}\end{array}$ \\
\hline
\end{tabular}

NOTE: Italic is used to denote that an overdue qualification was at stake (defined as at least 3 years without qualifying to the ACN finals). Italic bold is used to denote that a first-time qualification to the ACN finals was at stake. Due to the lack of conflict data, Mauritius is not included in the analysis despite of the fact that it did not qualified to the $2000 \mathrm{ACN}$ the last match-day. 
TABle A.10: BALANCE CHECK

\begin{tabular}{|c|c|c|c|c|}
\hline Variable & $\begin{array}{c}\text { Qualified } \\
\text { (1) }\end{array}$ & $\begin{array}{c}\text { Not Qualified } \\
\text { (2) }\end{array}$ & $\begin{array}{l}P \text {-Value of } \\
\text { Difference } \\
\text { (3) }\end{array}$ & $\begin{array}{c}\text { Within Qualification } \\
\text { Difference } \\
\text { (4) }\end{array}$ \\
\hline GDP per Capita & 1689.92 & 2252.11 & 0.396 & $\begin{array}{c}-515.812 \\
(568.896)\end{array}$ \\
\hline Poverty Rate & 0.49 & 0.44 & 0.246 & $\begin{array}{l}0.048 * \\
(0.025)\end{array}$ \\
\hline Gini Index & 44.18 & 44.49 & 0.826 & $\begin{array}{l}-0.119 \\
(2.282)\end{array}$ \\
\hline Life Expectancy & 53.82 & 54.17 & 0.785 & $\begin{array}{l}-0.447 \\
(0.930)\end{array}$ \\
\hline Population Density & 45.10 & 65.66 & 0.131 & $\begin{array}{l}-21.190 \\
(18.468)\end{array}$ \\
\hline Urban Population Rate & 37.88 & 38.25 & 0.909 & $\begin{array}{l}-0.175 \\
(2.775)\end{array}$ \\
\hline Autocracy & 1.64 & 2.31 & 0.081 & $\begin{array}{c}-0.674 * \\
(0.313)\end{array}$ \\
\hline Political Corruption & 0.66 & 0.72 & 0.084 & $\begin{array}{c}-0.065^{*} \\
(0.029)\end{array}$ \\
\hline Fraction Civil War 90's & 0.29 & 0.33 & 0.603 & $\begin{array}{l}-0.037 \\
(0.059)\end{array}$ \\
\hline Number of Conflicts & 0.30 & 0.26 & 0.696 & $\begin{array}{c}0.039 \\
(0.083)\end{array}$ \\
\hline
\end{tabular}

For a set of covariates (listed on the left) in the year before the end of each qualification process to the $\mathrm{ACN}$, columns (1) and (2) report the unconditional means for (barely) qualified countries (46 observations) and (barely) not qualified countries (55 observations). Column (3) reports the p-value associated with the mean difference test between (1) and (2). A second test is presented in column (4) which presents the OLS coefficients from separate regressions of each covariate on a treatment status (i.e, qualified) conditional on 9 qualification process dummies to ensure that comparison in the covariates is made between countries in the same year. $* * * \mathrm{p}<0.01$, ** $\mathrm{p}<0.05, * \mathrm{p}<0.1$. Robust standard errors in parentheses (in column 4). Each test includes 101 observations, except in poverty rate and Gini index with 100 observations. 
Table A.11: Impact of ACN Qualification on Conflict Prevalence (Probit)

\begin{tabular}{|c|c|c|c|c|}
\hline \multicolumn{5}{|c|}{ Dependent Variable: Conflict Prevalence ( 1 if at least one conflict in week, 0 otherwise) } \\
\hline & (1) & (2) & (3) & (4) \\
\hline Post-Qualification & $\begin{array}{c}-0.336 * * \\
(0.133)\end{array}$ & $\begin{array}{c}-0.301 * * * \\
(0.117)\end{array}$ & $\begin{array}{c}-0.200 * * \\
(0.079)\end{array}$ & $\begin{array}{c}-0.308 * * \\
(0.128)\end{array}$ \\
\hline Country $\times$ Qualifier FE & Yes & Yes & No & No \\
\hline Random Effect Model & No & No & No & Yes \\
\hline Qualifying Country Indicator & No & No & Yes & No \\
\hline 4 lags of Conflict & No & Yes & No & No \\
\hline Week FE & Yes & Yes & Yes & Yes \\
\hline Observations & 4,650 & 4,278 & 5,050 & 5,050 \\
\hline
\end{tabular}

Estimates from Probit regression models. $* * * \mathrm{p}<0.01, * * \mathrm{p}<0.05, * \mathrm{p}<0.1$ Robust standard errors in parentheses clustered at the country $\times$ qualifier level. Sample covers $+/-25$ weeks around the end of qualification process. Post-Qualification takes value 1 during the 25 weeks following the qualification to ACN, 0 otherwise. Conflict data comes from the ACLED dataset. 
TABLE A.12: IMPACT OF ACN QUALIFICATION ON CONFLICT INTENSITY (MAXIMUM-LiKelihoOd NegATIVE BINOMIAL)

\begin{tabular}{lcccc}
\hline \hline Dependent Variable: & \multicolumn{2}{c}{ Num. Events } & \multicolumn{2}{c}{ Num. Fatalities } \\
& $(1)$ & $(2)$ & $(3)$ & $(4)$ \\
\hline Post-Qualification & $-0.440^{* *}$ & $-0.332^{* *}$ & $-0.803^{* *}$ & $-0.797^{* *}$ \\
& $(0.194)$ & $(0.146)$ & $(0.327)$ & $(0.335)$ \\
\hline \multirow{2}{*}{ 4 lags of Conflict } & No & Yes & No & Yes \\
Country $\times$ Qualifier FE & Yes & Yes & Yes & Yes \\
Week FE & Yes & Yes & Yes & Yes \\
\hline Observations & 5,050 & 4,646 & 5,050 & 4,646 \\
\hline \hline
\end{tabular}

Estimates from negative binomial regression models. *** $\mathrm{p}<0.01, * * \mathrm{p}<0.05, * \mathrm{p}<0.1$ Robust standard errors in parentheses clustered at the country $\times$ qualifier level. Sample covers $+/-25$ weeks around the end of qualification process. Post-Qualification takes value 1 during the 25 weeks following the qualification to $\mathrm{ACN}, 0$ otherwise. Conflict data comes from the ACLED dataset.

\section{TABLE A.13: CONFLICT INTENSITY (IHS TRANSFORMATION)}

\begin{tabular}{|c|c|c|c|c|c|c|c|c|}
\hline \multirow{4}{*}{ Type of Conflict: } & \multicolumn{8}{|c|}{ Dependent Variable: Inverse Hyperbolic Sine Transformation of } \\
\hline & \multicolumn{4}{|c|}{ All } & \multicolumn{4}{|c|}{ Ethnic } \\
\hline & \multicolumn{2}{|c|}{ Num. Events } & \multicolumn{2}{|c|}{ Num. Fatalities } & \multicolumn{2}{|c|}{ Num. Events } & \multicolumn{2}{|c|}{ Num. Fatalities } \\
\hline & (1) & (2) & (3) & (4) & (5) & (6) & (7) & (8) \\
\hline Post-Qualification & $\begin{array}{c}-0.225 * * \\
(0.090)\end{array}$ & $\begin{array}{c}-0.136^{* * *} \\
(0.048)\end{array}$ & $\begin{array}{c}-0.265^{* *} \\
(0.106)\end{array}$ & $\begin{array}{c}-0.174 * * * \\
(0.066)\end{array}$ & $\begin{array}{c}-0.041 \\
(0.026)\end{array}$ & $\begin{array}{c}-0.028 * \\
(0.015)\end{array}$ & $\begin{array}{c}-0.088 * \\
(0.046)\end{array}$ & $\begin{array}{c}-0.068 * * \\
(0.031)\end{array}$ \\
\hline 4 lags of Conflict & No & Yes & No & Yes & No & Yes & No & Yes \\
\hline Country $\times$ Qualifier FE & Yes & Yes & Yes & Yes & Yes & Yes & Yes & Yes \\
\hline Week FE & Yes & Yes & Yes & Yes & Yes & Yes & Yes & Yes \\
\hline Observations & 5,050 & 4,646 & 5,050 & 4,646 & 5,050 & 4,646 & 5,050 & 4,646 \\
\hline R-squared & 0.013 & 0.111 & 0.012 & 0.068 & 0.010 & 0.080 & 0.011 & 0.061 \\
\hline
\end{tabular}

$* * * \mathrm{p}<0.01, * * \mathrm{p}<0.05, * \mathrm{p}<0.1$ Robust standard errors in parentheses clustered at the country $\times$ qualifier level. Sample covers $+/-25$ weeks around the end of qualification process. Post-Qualification takes value 1 during the 25 weeks following the qualification to ACN, 0 otherwise. Conflict data comes from the ACLED dataset. 
Table A.14: Close Qualifications to World CuP

\begin{tabular}{lccc}
\hline \hline Country & Year of Qualification & Qualification Status & Never Qualified Before \\
\hline ANGOLA & 1997 & 0 & 1 \\
CONGO & 1997 & 0 & 1 \\
CAMEROON & 1997 & 1 & 0 \\
SOUTH AFRICA & 1997 & 1 & 1 \\
IVORY COAST & 2001 & 0 & 1 \\
LIBERIA & 2001 & 0 & 1 \\
NIGERIA & 2001 & 1 & 0 \\
SENEGAL & 2001 & 1 & 1 \\
CAMEROON & 2005 & 0 & 0 \\
NIGERIA & 2005 & 0 & 0 \\
SENEGAL & 2005 & 0 & 0 \\
ANGOLA & 2005 & 1 & 1 \\
IVORY COAST & 2005 & 1 & 1 \\
TOGO & 2005 & 1 & 1 \\
GABON & 2009 & 0 & 1 \\
CAMEROON & 2009 & 1 & 0 \\
NIGERIA & 2009 & 1 & 0 \\
\hline \hline
\end{tabular}

Qualification Status takes the value of 1 if the national team qualified to the World Cup, 0 otherwise. Never Qualified Before takes the value of 1 the if the national team reached the last match-day with chances of qualifying to the World Cup for the very first time, 0 otherwise.

Table A.15: Pooling Close Qualifications to ACN and World CuP

\begin{tabular}{lcccccc}
\hline \hline Dependent Variable & \multicolumn{2}{c}{ Conflict Prevalence } & \multicolumn{2}{c}{ Num. Events $(\log +1)$} & \multicolumn{2}{c}{ Num. Fatalities $(\log +1)$} \\
& $(1)$ & $(2)$ & $(3)$ & $(4)$ & $(5)$ & $(6)$ \\
\hline Post-Qualification & $-0.065^{* *}$ & $-0.050^{* *}$ & $-0.125^{*}$ & $-0.065^{*}$ & $-0.153^{*}$ & -0.088 \\
& $(0.029)$ & $(0.025)$ & $(0.067)$ & $(0.037)$ & $(0.087)$ & $(0.056)$ \\
\hline 4 lags of Conflict & No & Yes & No & Yes & No & Yes \\
Country $\times$ Qualifier FE & Yes & Yes & Yes & Yes & Yes & Yes \\
Week FE & Yes & Yes & Yes & Yes & Yes & Yes \\
\hline Observations & 5,900 & 5,428 & 5,900 & 5,428 & 5,900 & 5,428 \\
R-squared & 0.009 & 0.023 & 0.010 & 0.113 & 0.007 & 0.060 \\
Number of Country-Qualifiers & 118 & 118 & 118 & 118 & 118 & 118 \\
\hline
\end{tabular}

$* * * \mathrm{p}<0.01, * * \mathrm{p}<0.05, * \mathrm{p}<0.1$ Robust standard errors in parentheses clustered at the country $\times$ qualifier level. Sample covers +/- 25 weeks around the end of qualification process. Post-Qualification takes value 1 during the 25 weeks following the qualification to $\mathrm{ACN}$ and $\mathrm{WC}, 0$ otherwise. Conflict data comes from the ACLED dataset. 


\section{TABle A.16: Close Qualifications to First World CuP}

\begin{tabular}{lcccccc}
\hline \hline Dependent Variable & \multicolumn{2}{c}{ Conflict Prevalence } & \multicolumn{3}{c}{ Num. Events $(\log +1)$} & \multicolumn{2}{c}{ Num. Fatalities $(\log +1)$} \\
& $(1)$ & $(2)$ & $(3)$ & $(4)$ & $(5)$ & $(6)$ \\
\hline Post-Qualification & $0.150^{* *}$ & $0.142^{* *}$ & $0.494^{*}$ & $0.358^{* *}$ & $0.711^{*}$ & $0.591^{*}$ \\
& $(0.068)$ & $(0.052)$ & $(0.243)$ & $(0.157)$ & $(0.337)$ & $(0.295)$ \\
First-Time x Post-Qualification & $-0.208^{* * *}$ & $-0.137^{*}$ & $-0.489^{*}$ & $-0.278^{*}$ & $-0.757^{* *}$ & -0.482 \\
& $(0.062)$ & $(0.067)$ & $(0.233)$ & $(0.159)$ & $(0.343)$ & $(0.300)$ \\
\hline \multirow{2}{*}{4 lags of Conflict } & No & Yes & No & Yes & No & Yes \\
Country $\times$ Qualifier FE & Yes & Yes & Yes & Yes & Yes & Yes \\
Week FE & Yes & Yes & Yes & Yes & Yes & Yes \\
\hline Observations & 850 & 782 & 850 & 782 & 850 & 782 \\
R-squared & 0.073 & 0.090 & 0.080 & 0.150 & 0.063 & 0.102 \\
Number of Country-Qualifiers & 17 & 17 & 17 & 17 & 17 & 17 \\
\hline
\end{tabular}

$* * * \mathrm{p}<0.01, * * \mathrm{p}<0.05, * \mathrm{p}<0.1$ Robust standard errors in parentheses clustered at the country $\times$ qualifier level. Sample covers +/- 25 weeks around the end of qualification process. Post-Qualification takes value 1 during the 25 weeks following the qualification to the World Cup, 0 otherwise. First-Time is a dummy indicating that the team reached the last match-day with chances of qualifying to the World Cup for the very first time. Conflict data comes from the ACLED dataset. 
TABLE A.17: URBAN vS RURAL CONFLICT

\begin{tabular}{lcccccc}
\hline \hline Dependent Variable & \multicolumn{2}{c}{ Conflict Prevalence } & \multicolumn{2}{c}{ Num. Events $(\log +1)$} & \multicolumn{2}{c}{ Num. Fatalities $(\log +1)$} \\
& $(1)$ & $(2)$ & $(3)$ & $(4)$ & $(5)$ & $(6)$ \\
\hline Post-Qualification & $-0.068^{* *}$ & $-0.065^{* *}$ & $-0.103^{* * *}$ & $-0.065^{* *}$ & -0.059 & $-0.124 * *$ \\
& $(0.028)$ & $(0.025)$ & $(0.030)$ & $(0.031)$ & $(0.039)$ & $(0.057)$ \\
\hline Conflict Sample & Urban & Rural & Urban & Rural & Urban & Rural \\
Mean Dep. Var. & 0.26 & 0.30 & 0.31 & 0.44 & 0.16 & 0.46 \\
Std Dev. Dep Var & 0.43 & 0.46 & 0.58 & 0.80 & 0.63 & 1.16 \\
4 lags of Conflict & No & Yes & No & Yes & No & Yes \\
Country $\times$ Qualifier FE & Yes & Yes & Yes & Yes & Yes & Yes \\
Week FE & Yes & Yes & Yes & Yes & Yes & Yes \\
\hline Observations & 4,646 & 4,646 & 4,646 & 4,646 & 4,646 & 4,646 \\
R-squared & 0.024 & 0.036 & 0.070 & 0.123 & 0.020 & 0.062 \\
\hline \hline
\end{tabular}

$* * * \mathrm{p}<0.01, * * \mathrm{p}<0.05, * \mathrm{p}<0.1$ Robust standard errors in parentheses clustered at the country $\times$ qualifier level. Sample covers $+/-25$ weeks around the end of qualification process. Post-Qualification takes value 1 during the 25 weeks following the qualification to ACN, 0 otherwise. Conflict data comes from the ACLED dataset. Urban areas in ? are used to code urban and rural events.

\section{Table A.18: Conflict Prevalence by Type of Conflict}

\begin{tabular}{|c|c|c|c|c|c|c|c|c|}
\hline \multirow[b]{4}{*}{ Post-Qualification } & \multicolumn{8}{|c|}{ Dependent Variable: Conflict Prevalence (if at least one conflict in week, 0 otherwise) } \\
\hline & \multicolumn{2}{|c|}{ Riots } & \multicolumn{2}{|c|}{ Attacks on Civilians } & \multicolumn{2}{|c|}{ Government } & \multicolumn{2}{|c|}{ Battles } \\
\hline & (1) & (2) & (3) & (4) & (5) & (6) & (7) & (8) \\
\hline & $\begin{array}{c}-0.089 * * * \\
(0.030)\end{array}$ & $\begin{array}{c}-0.083 * * * \\
(0.027)\end{array}$ & $\begin{array}{c}-0.063 * * \\
(0.029)\end{array}$ & $\begin{array}{c}-0.052^{* *} * \\
(0.024)\end{array}$ & $\begin{array}{l}-0.045 \\
(0.032)\end{array}$ & $\begin{array}{l}-0.043 * \\
(0.026)\end{array}$ & $\begin{array}{l}-0.014 \\
(0.024)\end{array}$ & $\begin{array}{l}-0.005 \\
(0.020)\end{array}$ \\
\hline 4 lags of Conflict & No & Yes & No & Yes & No & Yes & No & Yes \\
\hline Country $\times$ Qualifier FE & Yes & Yes & Yes & Yes & Yes & Yes & Yes & Yes \\
\hline Week FE & Yes & Yes & Yes & Yes & Yes & Yes & Yes & Yes \\
\hline Observations & 5,050 & 4,646 & 5,050 & 4,646 & 5,050 & 4,646 & 5,050 & 4,646 \\
\hline R-squared & 0.017 & 0.037 & 0.014 & 0.032 & 0.008 & 0.024 & 0.010 & 0.022 \\
\hline
\end{tabular}

*** $\mathrm{p}<0.01, * * \mathrm{p}<0.05, * \mathrm{p}<0.1$ Robust standard errors in parentheses clustered at the country $\times$ qualifier level. Sample covers $+/-25$ weeks around the end of qualification process. Post-Qualification takes value 1 during the 25 weeks after the qualification to ACN, 0 otherwise. Conflict data comes from the ACLED dataset. 
Table A.19: Conflict Intensity by Type of Conflict (Num. Events)

\begin{tabular}{|c|c|c|c|c|c|c|c|c|}
\hline \multirow[b]{4}{*}{ Post-Qualification } & \multicolumn{8}{|c|}{ Dependent Variable: Number of Conflict Events by Type $(\log +1)$} \\
\hline & \multicolumn{2}{|c|}{ Riots } & \multicolumn{2}{|c|}{ Attacks on Civilians } & \multicolumn{2}{|c|}{ Government } & \multicolumn{2}{|c|}{ Battles } \\
\hline & $(1)$ & $(2)$ & $(3)$ & $(4)$ & $(5)$ & $(6)$ & $(7)$ & $(8)$ \\
\hline & $\begin{array}{c}-0.124 * * * \\
(0.039)\end{array}$ & $\begin{array}{c}-0.100 * * * \\
(0.027)\end{array}$ & $\begin{array}{l}-0.084 \\
(0.051)\end{array}$ & $\begin{array}{c}-0.055^{*} \\
(0.029)\end{array}$ & $\begin{array}{c}-0.086 \\
(0.058)\end{array}$ & $\begin{array}{l}-0.051 \\
(0.033)\end{array}$ & $\begin{array}{l}-0.019 \\
(0.043)\end{array}$ & $\begin{array}{l}-0.000 \\
(0.026)\end{array}$ \\
\hline 4 lags of Conflict & No & Yes & No & Yes & No & Yes & No & Yes \\
\hline Country $\times$ Qualifier FE & Yes & Yes & Yes & Yes & Yes & Yes & Yes & Yes \\
\hline Week FE & Yes & Yes & Yes & Yes & Yes & Yes & Yes & Yes \\
\hline Observations & 5,050 & 4,646 & 5,050 & 4,646 & 5,050 & 4,646 & 5,050 & 4,646 \\
\hline R-squared & 0.018 & 0.085 & 0.012 & 0.070 & 0.008 & 0.096 & 0.011 & 0.093 \\
\hline
\end{tabular}

$* * * \mathrm{p}<0.01, * * \mathrm{p}<0.05, * \mathrm{p}<0.1$ Robust standard errors in parentheses clustered at the country $\times$ qualifier level. Sample covers $+/-25$ weeks around the end of qualification process. Post-Qualification takes value 1 during the 25 weeks following the qualification to ACN, 0 otherwise. Conflict data comes from the ACLED dataset.

TABle A.20: Conflict Intensity B y Type of Conflict (Num. Fatalities)

\begin{tabular}{lccccccccc}
\hline \hline \multirow{2}{*}{ Conflict Type: } & \multicolumn{7}{c}{ Dependent Variable: Number of Fatalities by Type (Log+1) } \\
& $(1)$ & $(2)$ & $(3)$ & $(4)$ & $(5)$ & $(6)$ & $(7)$ & $(8)$ \\
\hline \multirow{2}{*}{ Post-Qualification } & -0.004 & -0.011 & $-0.132^{* *}$ & $-0.112^{* *}$ & -0.112 & -0.066 & $-0.152^{* *}$ & $-0.106^{* *}$ \\
& $(0.017)$ & $(0.015)$ & $(0.062)$ & $(0.054)$ & $(0.073)$ & $(0.048)$ & $(0.074)$ & $(0.053)$ \\
\hline \multirow{2}{*}{ 4 lags of Conflict } & No & Yes & No & Yes & No & Yes & No & Yes \\
Country $\times$ Qualifier FE & Yes & Yes & Yes & Yes & Yes & Yes & Yes & Yes \\
Week FE & Yes & Yes & Yes & Yes & Yes & Yes & Yes & Yes \\
\hline Observations & 5,050 & 4,646 & 5,050 & 4,646 & 5,050 & 4,646 & 5,050 & 4,646 \\
R-squared & 0.011 & 0.020 & 0.011 & 0.022 & 0.009 & 0.035 & 0.011 & 0.047 \\
\hline \hline
\end{tabular}

$* * * \mathrm{p}<0.01, * * \mathrm{p}<0.05, * \mathrm{p}<0.1$ Robust standard errors in parentheses clustered at the country $\times$ qualifier level. Sample covers $+/-25$ weeks around the end of qualification process. Post-Qualification takes value 1 during the 25 weeks following the qualification to ACN, 0 otherwise. Conflict data comes from the ACLED dataset. 
TABle A.21: InCAPACITATION EFFECT DUE TO ACN FINALS?

\begin{tabular}{lcccccc}
\hline \hline Dependent Variable: & \multicolumn{2}{c}{ Conflict Prevalence } & \multicolumn{2}{c}{ Num. Events $(\log +1)$} & \multicolumn{2}{c}{ Num. Fatalities $(\log +1)$} \\
& $(1)$ & $(2)$ & $(3)$ & $(4)$ & $(5)$ & $(6)$ \\
\hline Post-Qualification & $-0.075^{* *}$ & $-0.065^{* *}$ & $-0.190^{* * *}$ & $-0.111^{* * *}$ & $-0.240^{* *}$ & $-0.157^{* * *}$ \\
& $(0.031)$ & $(0.027)$ & $(0.072)$ & $(0.037)$ & $(0.094)$ & $(0.060)$ \\
During ACN Finals & -0.024 & -0.027 & 0.100 & 0.050 & 0.134 & 0.101 \\
& $(0.043)$ & $(0.039)$ & $(0.092)$ & $(0.067)$ & $(0.152)$ & $(0.122)$ \\
\hline Country $\times$ Qualifier FE & Yes & Yes & Yes & Yes & Yes & Yes \\
Week FE & Yes & Yes & Yes & Yes & Yes & Yes \\
4 Lags of Conflict & No & Yes & No & Yes & No & Yes \\
\hline Observations & 5,050 & 4,646 & 5,050 & 4,646 & 5,050 & 4,646 \\
R-squared & 0.010 & 0.024 & 0.014 & 0.119 & 0.012 & 0.070 \\
\hline \hline
\end{tabular}

*** $\mathrm{p}<0.01, * * \mathrm{p}<0.05, * \mathrm{p}<0.1$ Robust standard errors in parentheses clustered at the country $\times$ qualifier level. Sample covers +/- 25 weeks around the end of qualification process. Post-Qualification takes value 1 during the 25 weeks following the qualification to ACN, 0 otherwise. The During ACN Finals takes value 1 for the qualified teams during the weeks in which the ACN finals are taking place, 0 otherwise. Conflict data comes from the ACLED dataset. 